bioRxiv preprint doi: https://doi.org/10.1101/2021.04.29.440076; this version posted May 5,2021 . The copyright holder for this preprint (which

was not certified by peer review) is the author/funder, who has granted bioRxiv a license to display the preprint in perpetuity. It is made available under aCC-BY-NC-ND 4.0 International license.

\title{
Life-histories as determinants of infection prevalence for trypanosomatids: A meta-
} analysis

\author{
Hawra, Al-Ghafli ${ }^{1}$, Seth, M. Barribeau ${ }^{1 *}$
}

[1] Department of Evolution, Ecology and Behaviour, Institute of Infection, Veterinary, and Ecological Sciences, University of Liverpool.

*sethb@liverpool.ac.uk 


\begin{abstract}
Trypanosomatids are a diverse family of protozoan parasites, some of which cause devastating human and livestock diseases. There are two distinct infection life-cycles in trypanosomatids; some species complete their entire life-cycle in a single host (monoxenous) while others infect two hosts (dixenous). Dixenous trypanosomatids are mostly vectored by insects, and the human trypanosomatid diseases are transmitted mainly by vectored parasites. While infection prevalence has been described for subsets of hosts and trypanosomatids, little is known about whether monoxenous and dixenous trypanosomatids differ in infection prevalence. Here, we use meta-analyses to synthesise all published evidence of trypanosomatid infection prevalence for the last two decades. We employed a semi-automated screening protocol, using machine learning algorithms and natural language processing, resulting in the qualitative inclusion of 569 citations and quantitative inclusion of 261 citations. We find striking difference in infection prevalence with monoxenous species having twice the infection prevalence $(19.8 \%)$ than dixenous species (8.68\%) in both insect and non-insect hosts and are more than three-fold more prevalent in insects (20.9\%) compared to their dixenous kins $(6.61 \%)$. We also find that dixenous trypanosomatids have lower infection prevalence among insects compared to their definitive hosts, which is consistent across dixenous genera. Within the monoxenous trypanosomatids, genera infecting bees are characterised with the highest prevalence, which does not vary between wild and managed bees. To our knowledge, these results reveal for the first time, a fundamental difference in infection prevalence according to host specificity where vectored species suffer from lower infection prevalence as a result of a 'jack of all trades, master of none' style trade-off between the vector and definitive host.
\end{abstract}




\section{Introduction}

Trypanosomatids are Kinetoplastid protozoan parasites that infect a diverse range of hosts including vertebrates, invertebrates and plants. Among trypanosomatids, there are two distinct life-histories with some infecting only a single host for their whole life-cycle (monoxenous), and others that require two hosts to complete their development (dixenous). The dixenous lifestyle is thought to be evolutionarily derived and has evolved independently multiple times among the Kinetoplastids. ${ }^{1}$ Dixenous trypanosomatids invariably include an insect vector that then transmits infection to a vertebrate or plant definitive host. Dixenous trypanosomatids consist of four main genera: Leishmania, Trypanosoma, Endotrypanum and Phytomonas. The vast majority of epidemiological and empirical evidence for all trypanosomatids comes from the former two genera (Leishmania and Trypansoma) as they are the most medically relevant. At least 20 species of Leishmania, cause cutaneous, mucocutaneous and visceral leishmaniasis; Trypanosoma cruzi causes Chagas disease and Trypanosoma brucei is the etiological agent of African sleeping sickness. These diseases cause more than 830,000 infections every year ${ }^{2}$, causing significant disease burden, and their control is challenging. Estimates of incidence and mortality vary but some studies predict that more than 1 million people contract leishmaniasis annually, including up to 700,000 visceral cases (which is fatal in $95 \%$ of cases), and a further 1 billion people are at risk of infection. ${ }^{3-5}$

Monoxenous trypanosomatids not only have a simpler life-cycle and narrower host specificity, usually in a single invertebrate host, but they are also more common, more ancient (but see), ${ }^{6}$ and more diverse than dixenous trypanosomatids. ${ }^{7}$ There are 17 currently described monoxenous trypanosomatids genera: Angomonas, Blastocrithidia, Blechomonas, Crithidia, Herpetomonas, Jaenimonas, Kentomonas, Lafontella, Leptomonas, Lotmaria, Novymonas, Paratrypanosoma, Rhynchoidomonas, Sergeia, Strigomonas, Wallacemonas, and Zelonia in contrast to the four dixenous genera. Despite the overwhelming diversity of monoxenous trypanosomatids we know comparatively little about their natural history and prevalence, due to their perceived lack of medical relevance - although this has been called into question recently by opportunistic vertebrate infections by some monoxenous trypanosomatids. ${ }^{8-10}$

Monoxenous and dixenous trypanosomatids also appear to differ in their infection prevalence. Despite the substantive health burden of vectored trypanosomatids, they have surprisingly low infection prevalence in the vector insects. For instance, fewer than 3\% of Phlebotomus sand flies carry Leishmania ${ }^{11}$ and as few as $0.1 \%$ of adult tsetse flies have transmissible Trypanosoma cells in their saliva. ${ }^{12}$ In contrast, trypanosomatids with only a single insect host can reach extremely high prevalence. In the bumblebee Bombus terrestris up to $35 \%$ of workers can be infected by its trypanosomatid parasite, Crithidia bombi. ${ }^{13}$ These data hint at something crucial: that perhaps the major limiting factor for trypanosomatid infection transmission is the vector, not the vertebrate host. Therefore, a detailed understanding of insect-parasite interactions, and how they can be manipulated, will be vital to the control and potential eradication of these diseases.

Here, we set out to systematically test whether monoxenous and dixenous trypanosomatids indeed have different infection prevalences, and whether this is 
consistent among hosts. While some systematic reviews have attempted to examine trypanosomatid pooled prevalence they have only done so in the context of either individual trypanosomatid or host taxa, ${ }^{14,15}$ or summarised evidence across hosts but were restricted to one geographic region. ${ }^{16-18}$ This is the first review of its type at this scale aimed to describe how fundamental aspects of parasite life-history influence disease prevalence in an important group of human, livestock, and wildlife parasites. We hope that our findings will help clarify the link between parasite life-history and infection in turn, potentially shed light onto better control strategies to combat the spread of trypanosomatid infections.

\section{Methodology}

\section{Literature search}

We searched Scopus and all available databases in Web of science, to identify all published studies that describe trypanosomatid prevalence in non-human hosts. Full search terms can be found in Supplementary Table 1. During the literature search, we did not apply any year or publication type restrictions (search stopped Jan 2020). To exhaustively find studies of neglected trypanosomatids, we further checked the references in relevant papers and added candidate citations to screening list of studies. All duplicate references were identified and removed.

\section{Relevant screening stages and design}

References were initially screened based on titles and abstracts manually by a single reviewer (HA) using Rayyan website as outlined in (Supplementary appendix). We further employed an automated second review protocol using Machine Learning Algorithm (MLA) and Natural Language Processing (NLP) during the initial screening phase, as has previously been suggested for large datasets ${ }^{19}$ (and detailed in (Supplementary appendix). All studies that received a manual or an automated "include" decision were subsequently subjected to further eligibility assessment by full-text review by two different reviewers (Figure.1). Inclusion and exclusion criteria, as well as detailed protocol of study selection and data extraction can be found in (Supplementary appendix).

\section{Selection of studies for meta-analysis}

After filtering, 569 studies, with 1031 prevalences, were included in subsequent analyses. As expected, fewer (16\%) of these were on non-human parasites. We included all of these studies in our meta-analysis. The remaining studies (84\%) were on vector-borne human parasites such as Leishmania and Trypanosoma species. To capture all of the information about the less commonly studied trypanosomatids but without processing all of the overrepresented parasites, we opted to qualitatively include only studies with $>400$ sampled individuals. To confirm that this did not introduce any bias, we randomly selected 20 citations with fewer than 400 individuals. We made this selection approach based on the following considerations: (I) studies with larger sample size would be closer to the true population prevalence, (II) have stronger impact on the meta-analysis and (III) when 
broken down to host and parasite taxa level they will remain statistically informative. As an additional confirmatory step, we compared the outcome and the fit of models with 261 studies (as per our selection strategy) or all of the studies $(n=569)$. To our assurance, while both models showed similar outcome, models with 265 studies had a better fit than the alternatives (i.e. lower AIC value: $\Delta 153$ ).

\section{Meta-analysis}

Estimates of proportion of infections were calculated using "metaphor" package ${ }^{20}$ with the variance stabilised by Freeman-Tukey double arcsine transformation. Pooled estimates were back-transformed for each analysis and multiplied by 100 to get the pooled prevalence. Publication bias was assessed using a funnel plot with trim and fill method and Egger's test. We employed a random effect multilevel model (rma.mv) with a nested random design to account for the heterogeneity of evidence either due to different study protocols and/or different host/parasite taxa within and between studies. We assigned "study ID" as an outer random factor, and both "host type: 19 levels" and "parasite taxa: 47 levels" were considered inner-random factors. This was done for the general model with no moderator applied as well as meta-regression models with the following moderators: diagnostic method (3 levels [molecular, microscopic, serological]), life-history traits of the parasite (3 levels[dixenous, monoxenous, mixed trypansomatids), host groups (insects and non-insects), parasite taxa (47 levels), host taxa (19 levels). We also ran similar metaregression models to assess pooled prevalence but in a subgroup of interest excluding some levels of the moderator as necessary . For instance, when comparing diagnostic methods among hosts we excluded serological approaches as they only apply to vertebrates. Between-study variation was assessed using the Higgins $\mathrm{I}^{2}$ statistic, which usually indicates substantial heterogeneity if exceeding 50\%. QM statistic, an omnibus test of all model coefficients except for the intercept, was conducted to conclude if a moderator significantly influences the mean effect size. All meta-regression models were run with and without the model intercept to statistically compare effect size of factors and generate pooled estimate for each factor respectively. Forest plots were presented using "orchaRd" package with "tanh" transformation as traditional forest plot will fail to present the large number of included citations. ${ }^{21}$ 


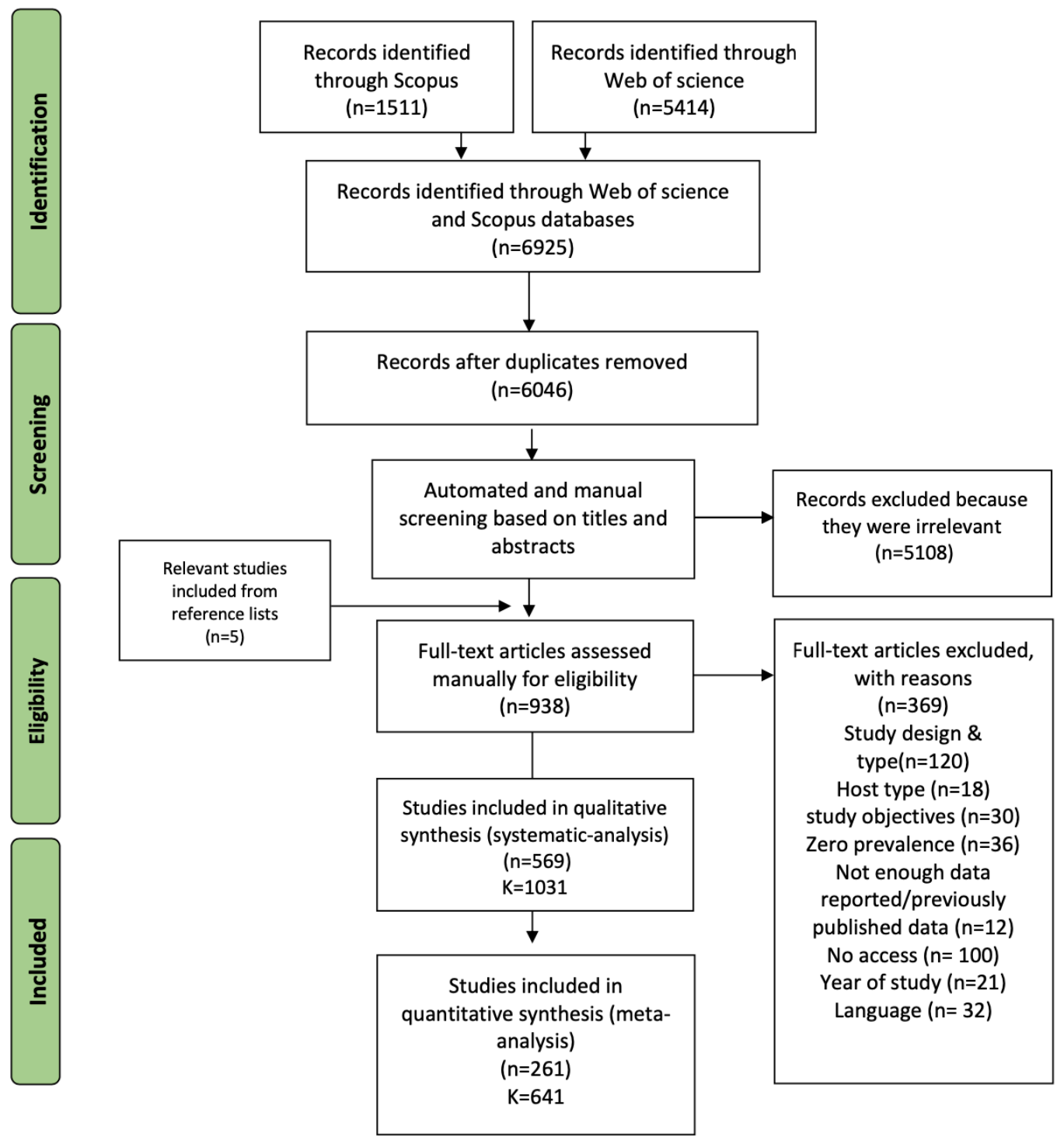

\section{Figure1: Selection and screening stages}

A) The overall protocol utilised for literature search and screening, wherein (n) represents the number of studies included/excluded at each stage and $(\mathrm{K})$ represents the number of data extracted from qualitatively or quantitatively included studies. All steps of the systematic review were in concordance with PRISMA guidelines. ${ }^{22}$ 


\section{Results}

\section{Exploring the impact of host-parasite traits on prevalence patterns}

Out of 6046 unique citations, we have qualitatively included 569 studies $^{23-591}$ and quantitatively included 261 studies. ${ }^{23-283}$ Overall, these results demonstrate a growing number of trypanosomatids studies over the last two decades (Supplementary Fig.2). Additional information about the geographic distribution of trypanosomatids can also be found in (Supplementary appendix).

A summary of the pooled prevalence and the main features of included citations, stratified by parasite species, can be found in Table 1 . We found that monoxenous parasites that usually infect the same host-order, show similar infection prevalence across hosts. This is the case both for monoxenous species with high prevalence (e.g. bees) and parasites with low pooled prevalence (e.g. monoxenous and dixenous species infecting flies)(Fig.2C). Subsequent analysis of various host-groupings show similar trends in infection prevalence in bees and flies to that presented in Table 1, though the latter remains influenced by both monoxenous and dixenous species (Supplementary Fig.6). In addition, fish, raccoons and buffaloes have high pooled prevalence although they are comparatively rarely studied (Supplementary Fig.3). In spite of the low number of studies, their total sample size indicates comparable robustness of analysis to that of other host groups, which supports our estimates of prevalence (Supplementary Fig.3B).

Infection prevalence is further stratified into within host prevalence in (Fig.2A). As expected, dogs and cats appear to be the main vertebrate-reservoirs for Leishmania and Trypanosoma cruzi. Additionally, the Trypanosoma congolense group seem to heavily infect certain domesticated animals such as pigs, sheep, and goats. Buffaloes, camels, and cattle appear to be the main reservoirs for Surra (Trypanosoma evansi). Some hosts have similar infection prevalence to various parasites of Trypanosomatidae (i.e. flies and rodents) while other parasite-groups show similar prevalence among various hosts (e.g. Trypanosoma simia).

\section{Multiple analysis of monoxenous versus dixenous infections}

We set out to test whether pooled prevalence of monoxenous infections differ from dixenous infections (both among insect and non-insect hosts). We find a strongly significant difference between pooled prevalence of monoxenous (19.8\%) and dixenous infections (8.68\%) (Fig.3A). Introducing "host-traits" as a sole moderator (i.e. insects and non-insects) reveals no significant difference between pooled prevalence of the two groups, $11.5 \%$ and $9.45 \%$ respectively (Fig.3B). Limiting the analysis to insects alone revealed an even stronger effect with monoxenous infections- three-fold more prevalent (20.9\%) than dixenous infections (6.61\%) (Fig.4, Table 2). We then compared prevalence in the groups of insects that had both dixenous and monoxenous parasites (true bugs and 
flies). Here however, we find non-significantly higher pooled prevalence for dixenous infections in flies and similar pooled prevalence in true bugs (Table 2).

Notably, dixenous parasites consistently infect 4.54-8.00\% of their insect hosts with no significant difference among parasite genera (Fig.4B). Common dixenous parasites, with prevalence data from both insects and non-insects, were significantly more prevalent in their non-insect hosts (9.38\%) than their insect hosts (5.51\%) (Table 2).

Monoxenous genera exhibit two alternative trends: high pooled prevalence for Lotmaria, jaculum and Crithidia species, but low pooled prevalence for Herpetomonas, Leptomonas, Agomonas, and Blastocrithidia groups (Fig.4 B). Taking into consideration that a considerable amount of monoxenous data (80\%) were on bee infections, we performed an in depth sub-group analysis to further understand the main drivers of bee infection prevalence. While the majority of included data represent natural infection among wild bees, the remaining evidence describes spillover of infections e.g. by sampling nonnative/commercial bees. We do not find any difference in trypanosomatid infection prevalence between wild-bees and commercial/managed bees for bumblebees or honeybees (Table 2).

Honeybee infections seem to predominantly occur in Western/European honeybees (e.g. Apis mellifera Linnaeus) compared to Asian honeybees (e.g. Apis dorsata Fabricius and Apis cerana Fabricius). We also noted a significant reduction in heterogeneity of evidence across all honeybee-infections due to spatial variations only ( $46 \%$ heterogeneity). However, a much higher diversity of infection prevalence was found in bumblebee taxa. Accounting for spatial and temporal factors failed to significantly reduce the heterogeneity in evidence for bumblebee infections, suggesting a unique impact of various bumblebee-trypanosomtids systems on different patterns of prevalence (Fig.2.B) and likely the greater diversity of bumblebees.

Diagnostic approach also affected infection prevalence but differ according to host. Microscopic diagnostics revealed higher infection prevalence in insects whereas molecular assays report higher infection prevalence in non-insects (Table 2). 

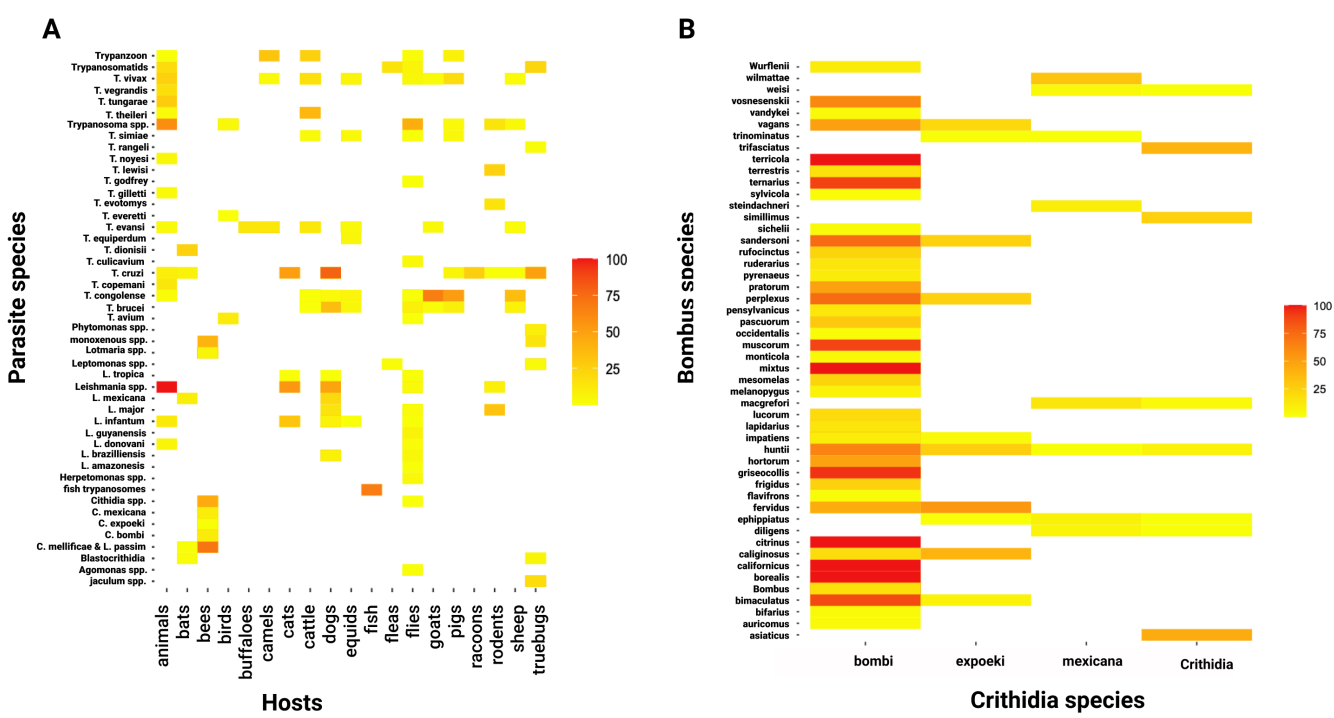

c

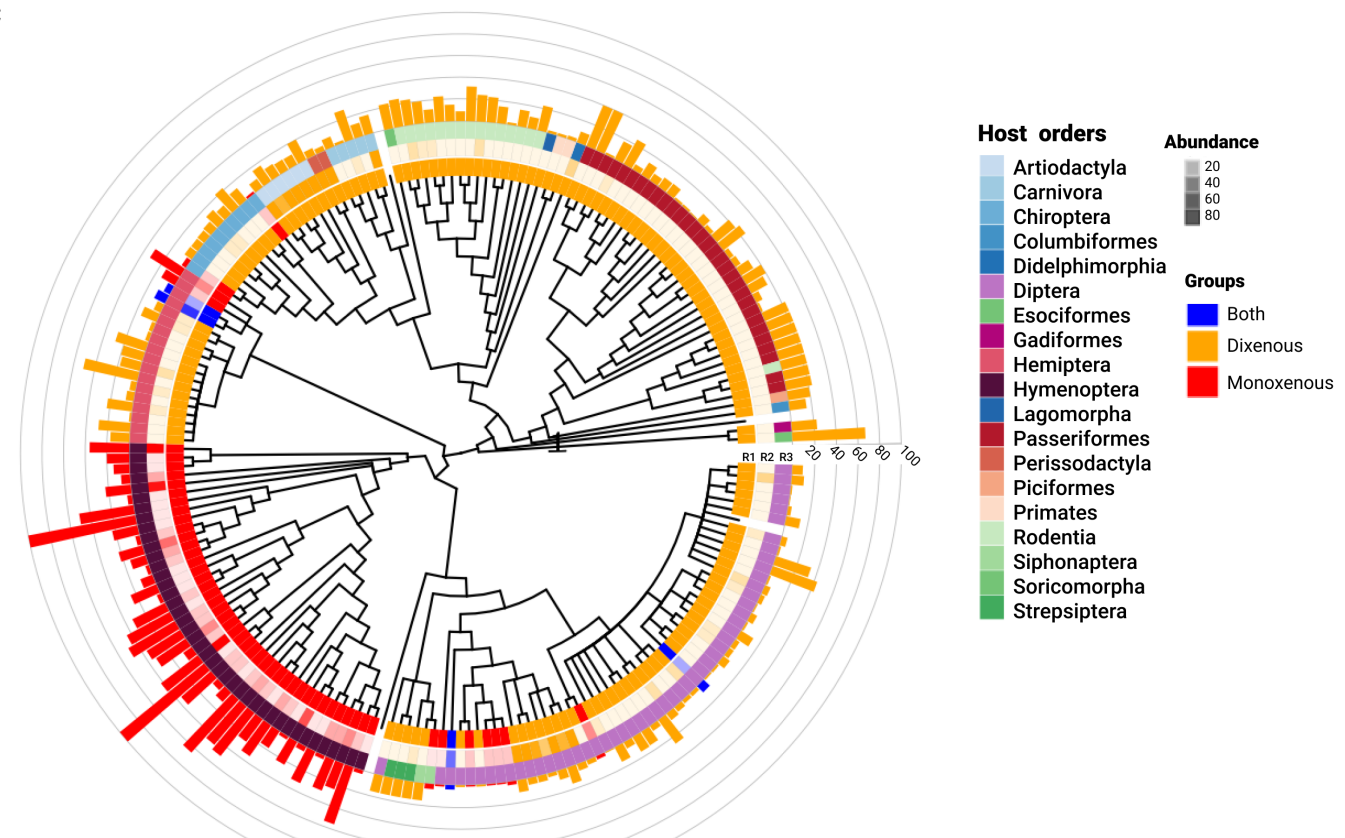

\section{Figure 2: Infection prevalence among host-trypanosomatid systems}

A heat-map of prevalence of all host-parasite systems (A), of bumblebee-trypanosomatids (B). A phylogenetic representation of all host taxa examined here. The first (inner) ring (R1) illustrates the parasite taxon's life-history (dixenous, monoxenous or both), the second ring (R2) highlights the abundance of prevalence data for each taxon, and the third ring (R3) is host order. Prevalence of infection (\%) is shown in the outer scaled ring, which is coloured according to parasite life-history. 


\section{A}

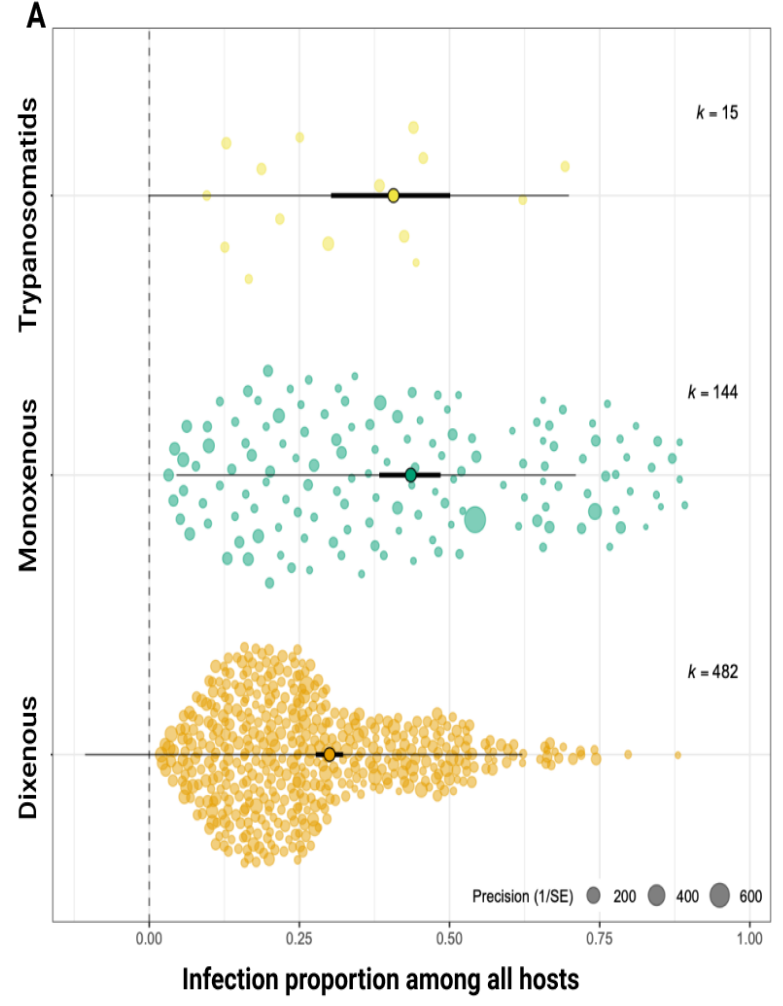

B

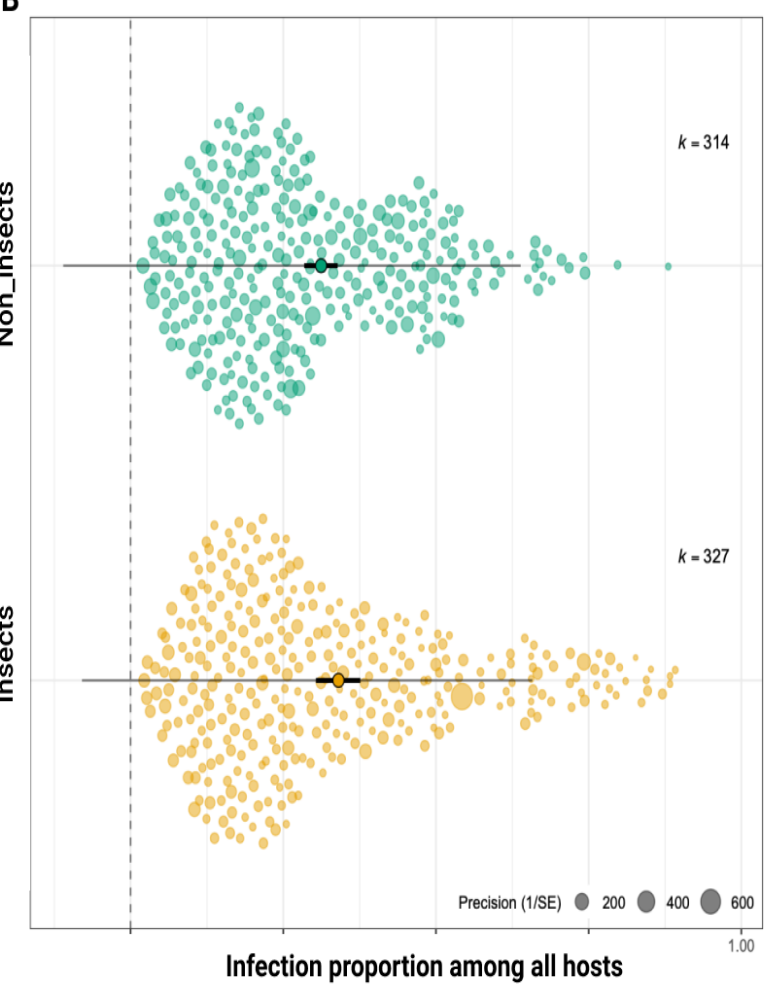

Figure 3: Forest plots of main meta-regression models

A) Pooled estimate of infection prevalence of dixenous $(0.310,95 \%$ CI:0.285, 0.335), monoxenous $(0.467,95 \%$ CI:0.404, 0.530), and mixed trypanosomatids $(0.427,95 \%$ CI:0.313, 0.551) with significant difference between them $(\mathrm{P}<0.05)$. These pooled estimates back-transform to $8.68 \%, 19.8 \%$, and $17.0 \%$, respectively. B) There is no overall significant difference between the pooled estimate of infection prevalence of insect $(0.354$, 95\% CI: $0.313,0.396)$ and non-insect $(0.320,95 \%$ CI:0.292, 0.353) hosts (P>0.05). These pooled estimates correspond to $11.5 \%$ and $9.45 \%$. 

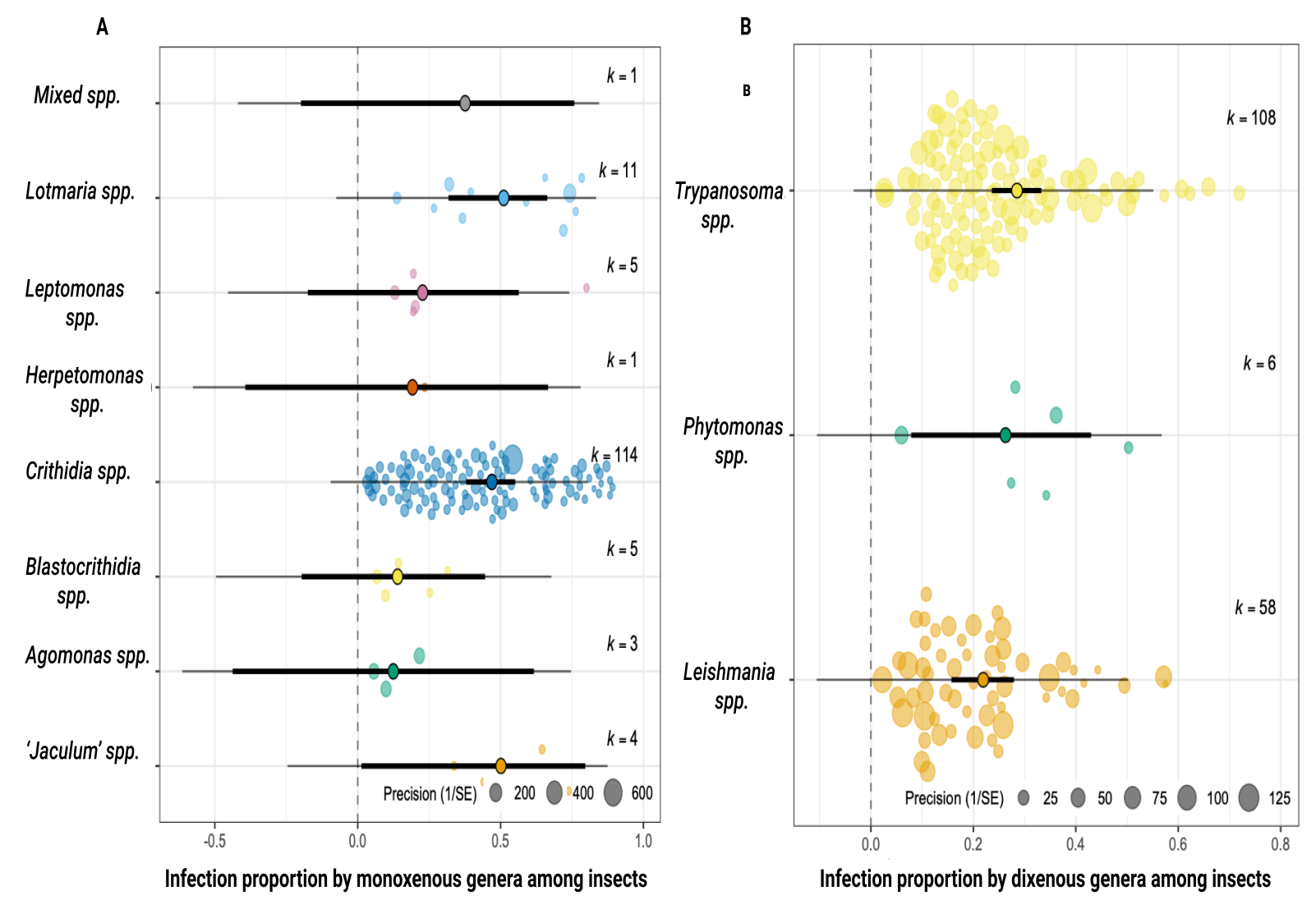

Figure 4: Forest plots of meta-regression models based on parasites-grouping among insects

A) Pooled estimate of infection prevalence of monoxenous genera, representing a pooled estimate of 0.395 (95\% CI:-0.201, 0.992), 0.566 (95\% CI:0.332, 0.801), 0.235 (95\% CI:0.1764, 0.6468), 0.197 (95\% CI:-0.415, 0.8085), 0.524 (95\% CI:0.4118, 0.6371), 0.158 (95\% CI:-0.2545, 0.5707), 0.125 (95\% CI: $-0.469,0.720)$ and 0.557 (95\% CI:0.012, 1.10) for monoxenous, Lotmaria, Leptomonas, Herpetomonas, Crithidia, Blastocrithidia, Angomonas and 'jaculum' species respectively with no significant difference between them $(\mathrm{P}>0.05)$. These pooled estimates were back-transformed to a prevalence of $13.4 \%, 27.9 \%, 3.70 \%$, $2.13 \%, 24.0 \%, 0.882 \%, 0.185 \%$ and $27.0 \%$. B) Pooled estimates of infection prevalence in dixenous genera, of 0.293 (95\% CI:0.2407, 0.3458), 0.269 (95\% CI:0.0786, 0.4597) and 0.223 (95\% CI:0.1586, 0.2868) for Trypanosoma, Phytomonas and Leishmania respectively with no significant difference between subgroups $(\mathrm{P}>0.05)$ corresponding to prevalence of $8.00 \%, 6.76 \%$ and $4.543 \%$.

\section{Discussion}

Trypanosomatid parasites have two distinct life-histories that vary in the number of host species and the complexity of their life-cycle. This difference is profound and will have commensurately profound effects on the evolution of parasite traits, including their ability 
to establish infection. How these alternative life-history strategies influence infection prevalence, however, is poorly understood. To our knowledge, this is the first comprehensive study designed to test for differences in infection prevalence. Our semiautomated screening protocol, resulted in the qualitative inclusion of 569 citations and quantitative inclusion of 261 citations.

We find that monoxenous trypanosomatids are far more prevalent in their hosts than are dixenous species. Across all hosts, we find at least two-fold higher prevalence in monoxenous species (Fig.3A) and more than three-fold higher when we examine infection prevalence in insects alone (Table 2). Taken together, one cannot escape the impression that complex parasite life-cycles have a cost to infection prevalence. In line with such speculation, high prevalence for monoxenous species was mainly notable among genera that infects bees such as Crithidia and Lotmaria with pooled prevalence of $24.0 \%$ and $27.9 \%$ respectively; ranking bees with the highest pooled prevalence among all insects $(26.3 \%)$. It is striking to realise that greater than a quarter of surveyed bees are infected by trypanosomatid pathogens. This is of a particular concern considering the crucial role of bees as pollinators, which, with other insect pollinators, account for the fertilisation of $83 \%$ of flowering plants ${ }^{592}$ including nutritionally and economically important crop species 593,594 . Bees and other pollinators have been declining. Among the presumed causes of pollinator declines are infectious diseases. ${ }^{595}$ Despite the attention that beetrypanosomatid infection has attracted, the distribution of interest remains uneven. Infection prevalence of trypanosomatids is largely unexplored outside of Europe and North America (Supplementary Fig.4)

The relationship between wild and managed bees, and the risk of spillover in either direction, has received particular attention and concern in the literature. While managed bees have been blamed for parasite transmission to wild bees, ${ }^{74,596}$ we find no significant difference between managed and wild honeybees and bumblebees (either independently or combined) in trypanosomatid infection prevalence. Whether this reflects shared susceptibility to infection or ongoing spillover to and from wild pollinators remains unknown.

To our knowledge this is the first study to provide such concise statistical summary of prevalence data among all host-trypanosomatids systems. Encouragingly, our findings recapitulate those of several other, taxon- or geographically-restricted, systematic reviews. For instance, A similar range of prevalence (2.4-9.2\%) for trypanosomatids was reported in sand-flies (Phlebotomus spp.) in Iran, ${ }^{597}$ which largely agrees with our finding of $2.02 \%$. Another meta-analysis on trypanosomatids in tsetse flies revealed a prevalence of $10 \%$, which is somewhat higher than we find in flies (5.51\%). ${ }^{15}$ The variation between these prevalence data could be due to different study design, year of publications of included studies and data analysis. Unlike our study, all prevalence data from ${ }^{15}$ were uncovered using microscopic examination and the analysis was done using STAT. Thus, although biting flies are responsible for most human trypanosomatids, our results seem to comport with previous studies revealing low infection prevalence in flies as a group, with no significant difference between monoxenous and dixenous parasites within flies (Table 2). Meanwhile, pooled prevalence for trypanosomosis in cattle, sheep and goats was reported 
as ranging between 1-9\%, which is comparable to what we find (Table 2. and Supplementary Fig.6).17,18,598

We also reveal significantly higher prevalence in the definitive vertebrate hosts than vector flies which is consistent among dixenous genera. This brings to the fore a possibility that dixenous trypanosomatids infect more of their vertebrate hosts than their insects vectors. Evolutionary theories predict a life history trade-off between investment in survival (within-host persistence and growth) and reproduction (between-host transmission). For dixenous trypanosomatids, such relationship is amplified by the number of host species needed to complete the life-cycle. ${ }^{599}$ This trend warrants further investigations as understanding how these species are maintained in the metapopulation holds great potential in managing the spread of vector-borne diseases. For instance, if the prevalence of infection in vectors is low, further reduction in insect hosts may better control infection in the metapopulation than suppression in vertebrate hosts.

In this study, we find that microscopic diagnostics revealed higher infection prevalence in insects but greater infection prevalence was revealed from molecular assays in non-insects (Table 2). This result does not necessarily indicate greater accuracy for either assay, but may rather indicate the preferred methodology of researchers working with insect versus vertebrate hosts. In line with this explanation, Abdi and researchers ${ }^{15}$ concluded that microscopic diagnostics were more common in surveys of tsetse flies than molecular assays and Aregawi et al. ${ }^{14}$ reported a higher range of prevalence (6-28\%) by molecular tests in vertebrates compared to microscopic tests (2-9\%) for the detection of Trypanosoma evansi. Standardising the diagnostic method applied for the detection of trypanosomatids within insects and non-insects is crucial consideration for future research to enable accurate comparisons of prevalence that is unlikely due variations in diagnostic protocols. We took this factor into consideration while doing all sub-group analysis (metaregression models) presented in this study to ensure that the difference in prevalence is real and not due to variable diagnostics. To our assurance, in all of the main subgroup analysis, there was no significant difference in pooled prevalence due different diagnostic tools. This is true for monoxenous or dixenous trypanosomatids in insects and dixenous trypanosomatids among vertebrate hosts (e.g. cats, dogs, rodents, goats, pigs, bats and buffaloes).

The key takeaway from this study is the unique pattern of infection prevalence in association with different life-history traits of trypanosomatids: revealing both (I) higher pooled prevalence for monoxenous species in insects and across all hosts, and (II) significantly lower prevalence among vectors compared to definitive hosts for dixenous species. We present three non-mutually exclusive arguments that could explain this finding:

- First, monoxenous species are subject to selection pressure from only one host, thereby affording these species more opportunity to adapt to this host than parasites that must co-evolve with both a vector and definitive host. We would thus expect to see greater parasite fitness in specialized monoxenous parasites than in dixenous parasites as the monoxenous parasites would arrive closer to their 
evolutionary optima. Dixenous parasites, in contrast, may be forced to trade-off infection relevant traits in one host for traits in the second host.

- $\quad$ Second, our finding may be the result of an equal force of infection shared among differing numbers of host species. Here, we offer a numerical explanation, where the same hypothetical number of infectious units are simply shared among more host species in dixenous parasites, thus diluting the infection prevalence in any one host species - to approximately half. This explanation is more than passingly similar to the "dilution effect" which is often, and sometimes controversially, used to describe infection risk in human populations when the natural host is not usually the human - eg. Lyme disease, ${ }^{600-602}$ although to our knowledge it has not been invoked to explain variation in infection prevalence among vectored and non-vectored parasites.

- $\quad$ Finally, host characteristics such as lifespan, recruitment rate, sociality, and physiology may explain some of the variation in infection prevalence. For instance, social bees, which have higher infection prevalence, differ from the rest of insect hosts not only in their sociality but also in their lifespan. The biological unit for social bees is the colony, which can extend the lifespan of an infection to at least a year (bumblebees) and to several years in honeybees. The other insect hosts live for up to a few months, and have high birth and death rates which, along with rarer direct interactions can reduce the overall prevalence of infection regardless of the parasite life-cycle strategy. Consistent with this view, we found low pooled prevalence among flies with no significant difference between monoxenous and dixenous species. Furthermore, flies might be physiologically harder to infect by trypanosomatids than bees as genomic studies have described a reduced immune repertoire in bees relative to dipterans. ${ }^{603,604}$

While this study was ambitious in scope and exhaustive in design, there are limitations. Foremost is the small number of studies describing prevalence in monoxenous species. But, as our analyses demonstrate earlier, this is more likely due to scarcity of publications for neglected trypanosomatids rather than study selection/handling approaches employed here. Finally, although this study is far-reaching and inclusive to all reported trypanosomatids systems contributing to slyvatic transmission cycles, it does not include humans as vertebrate hosts. Despite the exclusion of human infections, their impact and contribution to the transmission cycles either directly (to insects) or indirectly (to noninsects) have been accounted for by including studies surveying animals living nearby to humans. This includes pets (dogs, cats), domesticated animals, and the vectors, such as true bugs (tritomines), which are particularly found in houses. Thus, although the direct interaction in humans-trypanosomatids systems fall beyond the scope of this study, what we show here (i.e. how trypanosomatids differ in their infection prevalence among various non-human hosts) is particularly important to enable effective prevention plans for neglected tropical diseases of humans and livestock. Understanding the fundamental processes that determine infection prevalence will help us better understand trypanosomatids in general and identifying "weak-links" in the infection chain of vectored parasites - here in the vectored species, will enable better tailored control strategies for 
trypanosomatid diseases relevant to human, livestock, and wildlife health as well as foodsecurity.

\section{References}

1 Lukeš J, Skalický T, Týč J, Votýpka J, Yurchenko V. Evolution of parasitism in kinetoplastid flagellates. Molecular and Biochemical Parasitology 2014; 195: 115-22.

2 Global burden of disease (GBD). 2017; published online March.

3 Georgiadou SP, Makaritsis KP, Dalekos GN. Leishmaniasis revisited: Current aspects on epidemiology,diagnosis and treatment. J Transl Int Med 2015; 3: 43-50.

4 TDR. WHO | disease watch focus: leishmaniasis. Nat Rev Microbiol 2004.

$5 \quad$ Alvar IDAB Jorge AND Vélez. Leishmaniasis worldwide and global estimates of its incidence. PLOS ONE 2012; 7: 1-2.

6 Frolov AO, Malysheva MN, Yurchenko V, Kostygov AYu. Back to monoxeny: Phytomonas nordicus descended from dixenous plant parasites. European Journal of Protistology 2016; 52: 1-0.

$7 \quad$ Podlipaev S. The more insect trypanosomatids under study-the more diverse trypanosomatidae appears. International Journal for Parasitology 2001; 31: 648-52.

8 Ghosh S, Banerjee P, Sarkar A, Datta S, Chatterjee M. Coinfection of leptomonas seymouri and leishmania donovani in indian leishmaniasis. Journal of Clinical Microbiology 2012; 50: 2774-8.

9 Chicharro C, Alvar J. Lower trypanosomatids in HIV/AIDS patients. Annals of Tropical Medicine \& Parasitology 2003; 97: 75-8.

10 Ghobakhloo N, Motazedian MH, Naderi S, Ebrahimi S. Isolation of crithidia spp. From lesions of immunocompetent patients with suspected cutaneous leishmaniasis in iran. Tropical Medicine \& International Health 2019; 24: 116-26.

11 Tiwary P, Kumar D, Mishra M, Singh RP, Rai M, Sundar S. Seasonal variation in the prevalence of sand flies infected with leishmania donovani. PLoS One 2013; 8: e61370.

12 Stuart K, Brun R, Croft S, et al. Kinetoplastids: Related protozoan pathogens, different diseases. The Journal of clinical investigation 2008; 118: 1301-10.

13 Schmid-Hempel P, Wilfert L, Schmid-Hempel R. Pollinator diseases: The bombuscrithidia system. In: Wilson K, Fenton A, Tompkins D, eds. Wildlife disease ecology: Linking theory to data and application. Cambridge University Press, 2019: 3-1.

14 Aregawi A W. G., Abdi RD. Systematic review and meta-analysis on the global distribution, host range, and prevalence of trypanosoma evansi. Parasites Vectors 2019; 12. DOI:https://doi.org/10.1186/s13071-019-3311-4. 
15 Abdi A R. D., Duchateau L. A systematic review and meta-analysis of trypanosome prevalence in tsetse flies. BMC Vet Res 2017; 13: 100.

16 Correa JP, Bacigalupo A, Yefi-Quinteros E, et al. Trypanosomatid infections among vertebrates of chile: A systematic review. Pathogens 2020; 9.

DOI:10.3390/pathogens9080661.

17 Leta S, Alemayehu G, Tarekegn Z, Tessema MB. Prevalence of bovine trypanosomosis in ethiopia: A meta-analysis. Parasites \& Vectors 2016; 9. DOI:10.1186/s13071-016-1404-X.

18 Ebhodaghe F, Ohiolei JA, Isaac C. A systematic review and meta-analysis of small ruminant and porcine trypanosomiasis prevalence in sub-saharan africa (1986 to 2018). Acta Tropica 2018; 188: 118-31.

19 Marshall I, Wallace B. Toward systematic review automation: A practical guide to using machine learning tools in research synthesis. Systematic Reviews 2019; 8. DOI:10.1186/s13643-019-1074-9.

20 Viechtbauer W. Conducting meta-analyses in r with the metafor package. Journal of Statistical Software, Articles 2010; 36: 1-48.

21 Nakagawa S, Lagisz M, O'Dea RE, et al. The orchard plot: Cultivating a forest plot for use in ecology, evolution, and beyond. Research Synthesis Methods 2021; 12: 4-12.

22 Moher AAT David AND Liberati. Preferred reporting items for systematic reviews and meta-analyses: The PRISMA statement. PLOS Medicine 2009; 6: 1-6.

23 Abebe G R., Simon I. Bovine trypanosomosis and vector density in omo-ghibe tsetse belt, south ethiopia. Acta Trop 2017; 167: 79-85.

24 Adam M Y., Van den Bossche P. Bovine trypanosomosis in the upper west region of ghana: Entomological, parasitological and serological cross-sectional surveys. Res Vet Sci 2012; 92: 462-8.

25 Adams H E. R., Gibson WC. The identification, diversity and prevalence of trypanosomes in field caught tsetse in tanzania using ITS-1 primers and fluorescent fragment length barcoding. Infect Genet Evol 2008; 8: 439-44.

26 Ajaoud E-S M., Lemrani M. Phlebotomus sergenti in a cutaneous leishmaniasis focus in azilal province (high atlas, morocco): Molecular detection and genotyping of leishmania tropica, and feeding behavior. PLoS Negl Trop Dis 2015; 9: e0003687.

27 Akhoundi B M., Parvizi P. Molecular characterization of leishmania infection from naturally infected sand flies caught in a focus of cutaneous leishmaniasis (eastern iran). $J$ Arthropod Borne Dis 2013; 7: 122-31. 
28 Akhoundi M M., Mirzaei A. Molecular characterization of leishmania spp. In reservoir hosts in endemic foci of zoonotic cutaneous leishmaniasis in iran. Folia Parasitol (Praha) 2013; 60: 218-24.

29 Alanazi P A. D., Al-Shehri HR. Molecular detection of equine trypanosomiasis in the riyadh province of saudi arabia. J Vet Diagn Invest 2018; 30: 942-5.

30 Alanazi P A. D., Alraey YA. Molecular detection of leishmania spp. In skin and blood of stray dogs from endemic areas of cutaneous leishmaniasis in saudi arabia. Iran J Parasitol 2019; 14: 231-9.

31 Elsiddig M, Mohamed Y, Elshafie E, Alharbi Y, Al-Mekhlafi H. Molecular detection of trypanosoma evansi in camels (camelus dromedarius) in southwestern saudi arabia. The Thai veterinary medicine 2019; 49: 93-100.

32 Aleman G A., Hahn D. The prevalence of trypanosoma cruzi, the causal agent of chagas disease, in texas rodent populations. Ecohealth 2017; 14: 130-43.

33 Alias S S. N., Mohd-Zain SN. Epidemiology of blood parasitic infections in the urban rat population in peninsular malaysia. Trop Biomed 2014; 31: 230-40.

34 Amusategui AA I.Sainz. Annals of the new york academy of sciences. 2004: 154-7.

35 Anderson S J. M., Kamhawi S. Seasonality and prevalence of leishmania major infection in phlebotomus duboscqi neveu-lemaire from two neighboring villages in central mali. PLoS Negl Trop Dis 2011; 5: e1139.

36 Anez AV-D N.Rojas. Epidemiological study on visceral leishmaniasis in the semiarid region of western venezuela with special reference to inapparent infections. Boletin De Malariologia Y Salud Ambiental 2012; 52: 245-56.

37 Angwech N H., Skilton RA. Heterogeneity in the prevalence and intensity of bovine trypanosomiasis in the districts of amuru and nwoya, northern uganda. BMC Vet Res 2015; 11: 255.

38 Arismendi B N., Vargas M. PCR-specific detection of recently described lotmaria passim (trypanosomatidae) in chilean apiaries. J Invertebr Pathol 2016; 134: 1-5.

39 Astudillo H V. G., Yabsley MJ. Spatial, temporal, molecular, and intraspecific differences of haemoparasite infection and relevant selected physiological parameters of wild birds in georgia, USA. Int J Parasitol Parasites Wildl 2013; 2: 178-89.

40 Atarhouch R T., Dakkak A. Camel trypanosomosis in morocco 1: Results of a first epidemiological survey. Vet Parasitol 2003; 111: 277-86.

41 Athanasiou K L. V., Diakou A. A cross-sectional sero-epidemiological study of canine leishmaniasis in greek mainland. Acta Trop 2012; 122: 291-5.

42 Babuadze A G., Imnadze P. Epidemiology of visceral leishmaniasis in georgia. PLoS Negl Trop Dis 2014; 8: e2725. 
43 Bacigalupo T-P A., Cattan PE. Sylvatic foci of the chagas disease vector triatoma infestans in chile: Description of a new focus and challenges for control programs. Mem Inst Oswaldo Cruz 2010; 105: 633-41.

44 Bajer P A., Sinski E. Factors affecting the component community structure of haemoparasites in bank voles (clethrionomys glareolus) from the mazury lake district region of poland. Parasitology 2001; 122 Pt 1: 43-54.

45 Bamorovat S M., Keyhani A. Leishmania tropica in stray dogs in southeast iran. Iran J Public Health 2015; 44: 1359-66.

46 Batistoti C M., Jankevicius SI. Genetic variability of trypanosomatids isolated from phytophagous hemiptera defined by morphological, biochemical, and molecular taxonomic markers. J Parasitol 2001; 87: 1335-41.

47 Belo G V. S., Silva ES da. Reliability of techniques used in the diagnosis of canine visceral leishmaniasis by the national control program in brazil: A survey in an area of recent transmission. Prev Vet Med 2017; 146: 10-5.

48 Bento G-H E. C., Ramirez LE. Identification of bat trypanosomes from minas gerais state, brazil, based on $18 \mathrm{~S}$ rDNA and cathepsin-l-like targets. Parasitol Res 2018; 117: 73746.

49 Berlin N D., Baneth G. Prevalence of trypanosoma evansi in horses in israel evaluated by serology and reverse dot blot. Res Vet Sci 2012; 93: 1225-30.

50 Bernal XE, Pinto CM. Sexual differences in prevalence of a new species of trypanosome infecting tungara frogs. Int J Parasitol Parasites Wildl 2016; 5: 40-7.

51 Berzunza-Cruz R-M M., Becker I. Leishmania (l.) Mexicana infected bats in mexico: Novel potential reservoirs. PLoS Negl Trop Dis 2015; 9: e0003438.

52 Bezerra C C. M., Diotaiut L. Domestic, peridomestic and wild hosts in the transmission of trypanosoma cruzi in the caatinga area colonised by triatoma brasiliensis. Mem Inst Oswaldo Cruz 2014; 109: 887-98.

53 Bhattarai D N. R., Dujardin JC. Natural infection of phlebotomus argentipes with leishmania and other trypanosomatids in a visceral leishmaniasis endemic region of nepal. Trans R Soc Trop Med Hyg 2009; 103: 1087-92.

54 Birhanu F H., Buscher P. Epidemiology of trypanosoma evansi and trypanosoma vivax in domestic animals from selected districts of tigray and afar regions, northern ethiopia. Parasit Vectors 2015; 8: 212.

55 Biryomumaisho R S., Lubega GW. Livestock trypanosomosis in uganda: Parasite heterogeneity and anaemia status of naturally infected cattle, goats and pigs. Parasitol Res 2013; 112: 1443-50. 
56 Borghesan C T. C., Camargo EP. Genetic diversity and phylogenetic relationships of coevolving symbiont-harboring insect trypanosomatids, and their neotropical dispersal by invader african blowflies (calliphoridae). Front Microbiol 2018; 9: 131.

57 Botero T A., Thompson RC. Trypanosomes genetic diversity, polyparasitism and the population decline of the critically endangered australian marsupial, the brush tailed bettong or woylie (bettongia penicillata). Int J Parasitol Parasites Wildl 2013; 2: 77-89.

58 Boushaki A D., Kechemir Issad N. Epidemiological investigations on trypanosoma evansi infection in dromedary camels in the south of algeria. Heliyon 2019; 5: e02086.

59 Buendía M-H Maria, Higes M. Epidemiological study of honeybee pathogens in europe: The results of castilla-la mancha (spain). Spanish Journal of Agricultural Research 2018; 16. DOI:10.5424/sjar/2018162-11474.

60 Can D H., Guruz Y. Seroprevalence of leishmania infection and molecular detection of leishmania tropica and leishmania infantum in stray cats of izmir, turkey. Exp Parasitol 2016; 167: 109-14.

61 Cardia C D. F., Bresciani KD. Prevalence of toxoplasma gondii and leishmania spp. Infection in cats from brazil. Vet Parasitol 2013; 197: 634-7.

62 Cardinal O M. V., Gurtler RE. Heterogeneities in the ecoepidemiology of trypanosoma cruzi infection in rural communities of the argentinean chaco. Am J Trop Med Hyg 2014; 90 : 1063-73.

63 Cardoso R L., Schallig HD. Sero-epidemiological study of canine leishmania spp. Infection in the municipality of alijo (alto douro, portugal). Vet Parasitol 2004; 121: 21-32.

64 Carvalho W F. S., Rezende RP. Leishmania (viannia) braziliensis in dogs in brazil: Epidemiology, co-infection, and clinical aspects. Genet Mol Res 2015; 14: 12062-73.

65 Cassini S R., Pietrobelli M. Preliminary study of the effects of preventive measures on the prevalence of canine leishmaniosis in a recently established focus in northern italy. Vet Ital 2013; 49: 157-61.

66 Castillo-Neyra CC R., Levy MZ. The potential of canine sentinels for reemerging trypanosoma cruzi transmission. Prev Vet Med 2015; 120: 349-56.

67 Cavigli D I., Flenniken ML. Pathogen prevalence and abundance in honey bee colonies involved in almond pollination. Apidologie 2016; 47: 251-66.

68 Ceballos C L. A., Gurtler RE. Long-term reduction of trypanosoma cruzi infection in sylvatic mammals following deforestation and sustained vector surveillance in northwestern argentina. Acta Trop 2006; 98: 286-96.

69 Chagas S Ecds, Guerra M. Composition of sand fly fauna (diptera: Psychodidae) and detection of leishmania DNA (kinetoplastida: Trypanosomatidae) in different ecotopes from a rural settlement in the central amazon, brazil. Parasit Vectors 2018; 11: 180. 
70 Chargui H N., Babba H. Use of PCR, IFAT and in vitro culture in the detection of leishmania infantum infection in dogs and evaluation of the prevalence of canine leishmaniasis in a low endemic area in tunisia. Parasite 2009; 16: 65-9.

71 Chemkhi S J., Guerbouj S. Natural infection of algerian hedgehog, atelerix algirus (lereboullet 1842) with leishmania parasites in tunisia. Acta Trop 2015; 150: 42-51.

72 Cherenet S T., Bossche P van den. Seasonal prevalence of bovine trypanosomosis in a tsetse-infested zone and a tsetse-free zone of the amhara region, north-west ethiopia. Onderstepoort J Vet Res 2004; 71: 307-12.

73 Clausen C P. H., Schein E. A field study to estimate the prevalence of trypanosoma equiperdum in mongolian horses. Vet Parasitol 2003; 115: 9-18.

74 Colla 0 Sheila R., Thomson JD. Plight of the bumble bee: Pathogen spillover from commercial to wild populations. Biological Conservation 2006; 129: 461-7.

75 Comeaux C-R J. M., Hamer SA. Survey of feral swine ( sus scrofa) infection with the agent of chagas disease ( trypanosoma cruzi ) in texas, 2013-14. J Wildl Dis 2016; 52: 62730 .

76 Cordes H N., Solter LF. Interspecific geographic distribution and variation of the pathogens nosema bombi and crithidia species in united states bumble bee populations. $J$ Invertebr Pathol 2012; 109: 209-16.

77 Coura-Vital M W., Carneiro M. Prevalence and factors associated with leishmania infantum infection of dogs from an urban area of brazil as identified by molecular methods. PLoS Negl Trop Dis 2011; 5: e1291.

78 Cringoli R G., Capelli G. Serological survey of neospora caninum and leishmania infantum co-infection in dogs. Vet Parasitol 2002; 106: 307-13.

79 Crisante R G., Anez N. Infected dogs as a risk factor in the transmission of human trypanosoma cruzi infection in western venezuela. Acta Trop 2006; 98: 247-54.

80 D’Alvise S P., Hasselmann M. Seasonal dynamics and co-occurrence patterns of honey bee pathogens revealed by high-throughput RT-qPCR analysis. Ecol Evol 2019; 9: 10241-52.

81 D'Andrea FE L. A., Tolezano JE. The shadows of a ghost: A survey of canine leishmaniasis in presidente prudente and its spatial dispersion in the western region of sao paulo state, an emerging focus of visceral leishmaniasis in brazil. BMC Vet Res 2015; 11: 273.

82 Costa C da A. P., Marcili A. Trypanosoma cruzi and leishmania infantum chagasi infection in wild mammals from maranhao state, brazil. Vector Borne Zoonotic Dis 2015; 15: 656-66. 
83 Davison T H. C., Luckins AG. The occurrence of trypanosoma evansi in buffaloes in indonesia, estimated using various diagnostic tests. Epidemiol Infect 2000; 124: 163-72.

84 Almeida Ado S de B., Madeira Mde F. Canine visceral leishmaniasis: Seroprevalence and risk factors in cuiaba, mato grosso, brazil. Rev Bras Parasitol Vet 2012; 21: 359-65.

85 Avelar B de D. M., Linardi PM. Endosymbionts of ctenocephalides felis felis (siphonaptera: Pulicidae) obtained from dogs captured in belo horizonte, minas gerais, brazil. J Invertebr Pathol 2007; 94: 149-52.

86 Carvalho L A. G., Fontes CJF. High seroprevalence and peripheral spatial distribution of visceral leishmaniasis among domestic dogs in an emerging urban focus in central brazil: A cross-sectional study. Pathog Glob Health 2018; 112: 29-36.

87 Matos C Amrn, Navarro IT. Antibodies anti-trypanosomatides in domestic cats in parana: Who is at highest risk of infection? Rev Bras Parasitol Vet 2018; 27: 232-6.

88 Paula C M. B., Costa-Cruz JM. Occurrence of positivity for trypanosoma cruzi in triatomine from municipalities in southeastern brazil, from 2002 to 2004. Rev Soc Bras Med Trop 2010; 43: 9-14.

89 Thoisy M de B., Vie JC. A survey of hemoparasite infections in free-ranging mammals and reptiles in french guiana. J Parasitol 2000; 86: 1035-40.

90 Delafosse A, Doutoum AA. Prevalence of trypanosoma evansi infection and associated risk factors in camels in eastern chad. Vet Parasitol 2004; 119: 155-64.

91 Delafosse T A., Michaux Y. Epidemiology of trypanosoma vivax infection in cattle in the tse-tse free area of lake chad. Prev Vet Med 2006; 74: 108-19.

92 Dennis D J. W., MacLeod ET. Sodalis glossinidius prevalence and trypanosome presence in tsetse from luambe national park, zambia. Parasit Vectors 2014; 7: 378.

93 Desquesnes K M., Jittapalapong S. Antibody-ELISA for trypanosoma evansi: Application in a serological survey of dairy cattle, thailand, and validation of a locally produced antigen. Prev Vet Med 2009; 90: 233-41.

94 Dias R-S E. S., Fortes-Dias CL. Eco-epidemiology of visceral leishmaniasis in the urban area of paracatu, state of minas gerais, brazil. Vet Parasitol 2011; 176: 101-11.

95 Dias T-S R. C. F., Navarro IT. Variables associated with the prevalence of antileishmania spp. Antibodies in dogs on the tri-border of foz do iguacu, parana, brazil. Rev Bras Parasitol Vet 2018; 27: 338-47.

96 Dorn D P. L., Phillippi-Falkenstein KM. Low prevalence of chagas parasite infection in a nonhuman primate colony in louisiana. J Am Assoc Lab Anim Sci 2012; 51: 443-7.

97 Elmayan T A., Dumonteil E. High prevalence of trypanosoma cruzi infection in shelter dogs from southern louisiana, USA. Parasit Vectors 2019; 12: 322. 
98 Elshafie RAH E. I.Sani. Active infection and morphometric study of trypanosoma evansi among horses in peninsula malaysia. Tropical Biomedicine 2013; 30: 444-50.

99 Felipe A I. M., Caldas Ade J. Leishmania infection in humans, dogs and sandflies in a visceral leishmaniasis endemic area in maranhao, brazil. Mem Inst Oswaldo Cruz 2011; 106: 207-11.

100 Fernandez-Bellon S-G H., Ramis A. Little evidence of seasonal variation of natural infection by leishmania infantum in dogs in spain. Vet Parasitol 2008; 155: 32-6.

101 Ferroglio B E., Biglino A. Epidemiological evaluation of leishmania infantum zoonotic transmission risk in the recently established endemic area of northwestern italy. Zoonoses Public Health 2018; 65: 675-82.

102 Figueiredo M F. B., Schubach TM. Canine visceral leishmaniasis: Study of methods for the detection of IgG in serum and eluate samples. Rev Inst Med Trop Sao Paulo 2010; 52: 193-6.

103 Fikru G R., Buscher P. Widespread occurrence of trypanosoma vivax in bovines of tsetse- as well as non-tsetse-infested regions of ethiopia: A reason for concern? Vet Parasitol 2012; 190: 355-61.

104 Franca-Silva da C J. C., Nascimento E. Epidemiology of canine visceral leishmaniosis in the endemic area of montes claros municipality, minas gerais state, brazil. Vet Parasitol 2003; 111: 161-73.

105 Freitas N R. A., Barrett TV. Species diversity and flagellate infections in the sand fly fauna near porto grande, state of amapa, brazil (diptera: Psychodidae. Kinetoplastida: trypanosomatidae). Mem Inst Oswaldo Cruz 2002; 97: 53-9.

106 Fujimori A M.de Almeida. Prevalence and associated factors of canine visceral leishmaniasis in an endemic area of mato grosso, brazil. Acta Scientiae Veterinariae 2016; 44. <Go to ISI>://WOS:000392090700003.

107 Gallot-Lavallee S-H M., Schmid-Hempel P. Large scale patterns of abundance and distribution of parasites in mexican bumblebees. J Invertebr Pathol 2016; 133: 73-82.

108 Galvez M R., Molina R. Emerging trends in the seroprevalence of canine leishmaniasis in the madrid region (central spain). Vet Parasitol 2010; 169: 327-34.

109 Galvis-Ovallos C F., Galati EAB. Ecological parameters of the (s)-9methylgermacrene-b population of the lutzomyia longipalpis complex in a visceral leishmaniasis area in sao paulo state, brazil. Parasit Vectors 2017; 10: 269.

110 Garcia R H. A., Teixeira MMG. Remarkable richness of trypanosomes in tsetse flies (glossina morsitans morsitans and glossina pallidipes) from the gorongosa national park and niassa national reserve of mozambique revealed by fluorescent fragment length barcoding (FFLB). Infect Genet Evol 2018; 63: 370-9. 
111 Garcia G H., Mendoza-Leon A. Trypanosomiasis in venezuelan water buffaloes: Association of packed-cell volumes with seroprevalence and current trypanosome infection. Ann Trop Med Parasitol 2006; 100: 297-305.

112 Garvin S M. C., Moore FR. Blood parasites of nearctic-neotropical migrant passerine birds during spring trans-gulf migration: Impact on host body condition.J Parasitol 2006; 92: 990-6.

113 Gebre-Michael B T., Gramiccia M. The isolation of leishmania tropica and l. Aethiopica from phlebotomus (paraphlebotomus) species (diptera: Psychodidae) in the awash valley, northeastern ethiopia. Trans R Soc Trop Med Hyg 2004; 98: 64-70.

114 Ghawar T W., Ben-Salah A. Leishmania major infection among psammomys obesus and meriones shawi: Reservoirs of zoonotic cutaneous leishmaniasis in sidi bouzid(central tunisia). Vector Borne Zoonotic Dis 2011; 11: 1561-8.

115 Gillespie S. Factors affecting parasite prevalence among wild bumblebees. Ecological Entomology 2010; 35: 737-47.

116 Gillingwater M K., Majiwa PA. Prevalence of mixed trypanosoma congolense infections in livestock and tsetse in KwaZulu-natal, south africa. J S Afr Vet Assoc 2010; 81: 219-23.

117 Giorgobiani C E., Sacks D. Epidemiologic aspects of an emerging focus of visceral leishmaniasis in tbilisi, georgia. PLoS Negl Trop Dis 2011; 5: e1415.

118 Gizzarelli FM M., Maurelli MP. Simultaneous detection of parasitic vector borne diseases: A robust cross-sectional survey in hunting, stray and sheep dogs in a mediterranean area. Front Vet Sci 2019; 6: 288.

119 Godoi S M. M., Camargo EP. A PCR-based survey on phytomonas (euglenozoa: Trypanosomatidae) in phytophagous hemipterans of the amazon region. J Eukaryot Microbiol 2002; 49: 275-9.

120 Goossens M B., Vreysen M. Trypanosomosis prevalence in cattle on mafia island (tanzania). Vet Parasitol 2006; 139: 74-83.

121 Goulson 0 Dave, Park KJ. The impacts of predators and parasites on wild bumblebee colonies. Ecological Entomology 2018; 43: 168-81.

122 Goulson W Dave, Fowley M. Influence of urbanisation on the prevalence of protozoan parasites of bumblebees. Ecological Entomology 2012; 37: 83-9.

123 Greenaway C, Castelli F. Migration medicine. Infect Dis Clin North Am 2019; 33: 26587.

124 Grijalva V M. J., Baus EG. Comprehensive survey of domiciliary triatomine species capable of transmitting chagas disease in southern ecuador. PLoS Negl Trop Dis 2015; 9: e0004142. 
125 Grybchuk-Ieremenko L A., Yurchenko V. High prevalence of trypanosome coinfections in freshwater fishes. Folia Parasitol (Praha) 2014; 61: 495-504.

126 Gutierrez J C., Montoya JA. Camel trypanosomosis in the canary islands: Assessment of seroprevalence and infection rates using the card agglutination test (CATT/t. Evansi) and parasite detection tests. Veterinary Parasitology 2000; 90: 155-9.

127 Hagos A A., Claes F. Serological and parasitological survey of dourine in the arsi-bale highlands of ethiopia. Trop Anim Health Prod 2010; 42: 769-76.

128 Hagos D A., Goddeeris BM. Seroepidemiological survey of trypanozoon infection in horses in the suspected dourine-infected bale highlands of the oromia region, ethiopia. Rev Sci Tech 2010; 29: 649-54.

129 Hamel S D., Rehbein S. Parasites and vector-borne pathogens in client-owned dogs in albania. Blood pathogens and seroprevalences of parasitic and other infectious agents. Parasitol Res 2016; 115: 489-99.

130 Hauptmanova VL K.Benedikt. Blood parasites in passerine birds in slovakian east carpathians. Acta Protozoologica 2006; 45: 105-9.

131 Herrera D H. M., Jansen AM. Enzootiology of trypanosoma evansi in pantanal, brazil. Vet Parasitol 2004; 125: 263-75.

132 Hodo G C. L., Hamer SA. Trypanosome species, including trypanosoma cruzi, in sylvatic and peridomestic bats of texas, USA. Acta Trop 2016; 164: 259-66.

133 Hosseininejad MH M.Mohebali. Seroprevalence of canine visceral leishmaniasis in asymptomatic dogs in iran. Iranian Journal of Veterinary Research 2012; 13: 54-7.

134 Isaac C C., Turner CM. Molecular identification of different trypanosome species and subspecies in tsetse flies of northern nigeria. Parasit Vectors 2016; 9: 301.

135 Jabal-Uriel M-H Clara, De la Rua P. Short communication: First data on the prevalence and distribution of pathogens in bumblebees (bombus terrestris and bombus pascuorum) from spain. Spanish Journal of Agricultural Research 2017; 15. DOI:10.5424/sjar/2017151-9998.

136 Jaimes-Duenez Z-Z J., Mejia-Jaramillo AM. Evaluation of an alternative indirectELISA test using in vitro-propagated trypanosoma brucei brucei whole cell lysate as antigen for the detection of anti-trypanosoma evansi IgG in colombian livestock. Prev Vet Med 2019; 169: 104712.

137 Jaimes-Duenez T-C J., Mejia-Jaramillo AM. Parasitological and molecular surveys reveal high rates of infection with vector-borne pathogens and clinical anemia signs associated with infection in cattle from two important livestock areas in colombia. Ticks Tick Borne Dis 2017; 8: 290-9. 
138 Jiang W W., Wang Q. Seroepidemiological study of canine leishmania infantum and toxoplasma gondii infections in shanghai, china, and analysis of risk factors. Ann Agric Environ Med 2016; 23: 420-4.

139 Karakus T M., Ozbel Y. Evaluation of conjunctival swab sampling in the diagnosis of canine leishmaniasis: A two-year follow-up study in cukurova plain, turkey. Vet Parasitol 2015; $214:$ 295-302.

140 Karlsbakk E. Prevalence of trypanosome infections in marine fishes from western norway. Sarsia 2010; 89: 459-66.

141 Karshima A S. N., Mohammed G. Eco-epidemiology of porcine trypanosomosis in karim lamido, nigeria: Prevalence, seasonal distribution, tsetse density and infection rates. Parasit Vectors 2016; 9: 448.

142 Kassahun S A., Votypka J. Detection of leishmania donovani and l. Tropica in ethiopian wild rodents. Acta Trop 2015; 145: 39-44.

143 Katakweba M Abdul A. S., Belmain SR. Prevalence of haemoparasites, leptospires and coccobacilli with potential for human infection in the blood of rodents and shrews from selected localities in tanzania, namibia and swaziland†. African Zoology 2012; 47: 119-27.

144 Kato G Hirotomo, Cáceres AG. Molecular mass screening to incriminate sand fly vectors of andean-type cutaneous leishmaniasis in ecuador and peru. The American Journal of Tropical Medicine and Hygiene 2008; 79: 719-21.

145 Kato C H., Hashiguchi Y. First evidence of a hybrid of leishmania (viannia) braziliensis/l. (V.) Peruviana DNA detected from the phlebotomine sand fly lutzomyia tejadai in peru. PLoS Negl Trop Dis 2016; 10: e0004336.

146 Khan ASH A. U.Qureshi. Molecular identification of trypanosomes and their effects on hematological and biochemical parameters in donkeys in punjab, pakistan. International Journal of Agriculture and Biology 2018; 20: 1607-12.

147 Kidanemariam H A., Sahle M. Parasitological prevalence of bovine trypanosomosis in kindo koisha district, wollaita zone, south ethiopia. Onderstepoort J Vet Res 2002; 69: 10713.

148 Kissinger C C. N., Solter LF. Survey of bumble bee (bombus) pathogens and parasites in illinois and selected areas of northern california and southern oregon.J Invertebr Pathol 2011; 107: 220-4.

149 Kocher D A., Jittapalapong S. Evaluation of an indirect-ELISA test for trypanosoma evansi infection (surra) in buffaloes and its application to a serological survey in thailand. Biomed Res Int 2015; 2015: 361037.

150 Korner P, Schmid-Hempel P. Correlates of parasite load in bumblebees in an alpine habitat. Entomological Science 2005; 8: 151-60. 
151 Kouam D M. K., Theodoropoulos G. A seroepidemiological study of exposure to toxoplasma, leishmania, echinococcus and trichinella in equids in greece and analysis of risk factors. Vet Parasitol 2010; 170: 170-5.

152 Kozminsky K E., Maslov DA. Host-specificity of monoxenous trypanosomatids: Statistical analysis of the distribution and transmission patterns of the parasites from neotropical heteroptera. Protist 2015; 166: 551-68.

153 Lana M R. S., Dias ES. Ecoepidemiological aspects of visceral leishmaniasis in an endemic area in the steel valley in brazil: An ecological approach with spatial analysis. PLoS One 2018; 13: e0206452.

154 Laohasinnarong G D., Namangala B. Studies of trypanosomiasis in the luangwa valley, north-eastern zambia. Parasit Vectors 2015; 8: 497.

155 Lardeux A F., Depickere S. Bias due to methods of parasite detection when estimating prevalence of infection of triatoma infestans by trypanosoma cruzi. J Vector Ecol 2016; 41: 285-91.

156 Lauricella S M. A., Gurtler RE. Distribution and pathogenicity of trypanosoma cruzi isolated from peridomestic populations of triatoma infestans and triatoma guasayana from rural western argentina. Mem Inst Oswaldo Cruz 2005; 100: 123-9.

157 Leal C G. G. A., Coura-Vital W. Risk profile for leishmania infection in dogs coming from an area of visceral leishmaniasis reemergence. Prev Vet Med 2018; 150: 1-7.

158 Lledo G-P L., Serrano JL. Wild red foxes (vulpes vulpes) as sentinels of parasitic diseases in the province of soria, northern spain. Vector Borne Zoonotic Dis 2015; 15: 7439.

159 Lopez-Cespedes L A., Marin C. Leishmania spp. Epidemiology of canine leishmaniasis in the yucatan peninsula. ScientificWorldJournal 2012; 2012: 945871.

160 Lopez-Cespedes L A., Marin C. Seroprevalence of antibodies against the excreted antigen superoxide dismutase by trypanosoma cruzi in dogs from the yucatan peninsula (mexico). Zoonoses Public Health 2013; 60: 277-83.

161 Machila S N., Eisler MC. Antibody-ELISA seroprevalence of bovine trypanosomosis in the eastern province of zambia. Prev Vet Med 2001; 49: 249-57.

162 Magallon-Gastelum L-K E., Breniere SF. Epidemiological risk for trypanosoma cruzi transmission by species of phyllosoma complex in the occidental part of mexico. Acta Trop 2006; 97: 331-8.

163 Maia R C., Campino L. Bacterial and protozoal agents of feline vector-borne diseases in domestic and stray cats from southern portugal. Parasit Vectors 2014; 7: 115. 
164 Majekodunmi F A. O., Welburn SC. A longitudinal survey of african animal trypanosomiasis in domestic cattle on the jos plateau, nigeria: Prevalence, distribution and risk factors. Parasit Vectors 2013; 6: 239.

165 Malele C Imna, Gibson W. The use of specific and generic primers to identify trypanosome infections of wild tsetse flies in tanzania by PCR. Infection, Genetics and Evolution 2003; 3: 271-9.

166 Malfi RL, Roulston TH. Patterns of parasite infection in bumble bees (bombusspp.) Of northern virginia. Ecological Entomology 2014; 39: 17-29.

167 Maloney N J., Moncayo AC. Seroprevalence of trypanosoma cruzi in raccoons from tennessee. J Parasitol 2010; 96: 353-8.

168 Mamoudou N A., Achukwi MD. Animal trypanosomosis in clinically healthy cattle of north cameroon: Epidemiological implications. Parasit Vectors 2016; 9: 206.

169 Marti E G. A., Garcia JJ. Prevalence and distribution of parasites and pathogens of triatominae from argentina, with emphasis on triatoma infestans and triatoma virus TrV.J Invertebr Pathol 2009; 102: 233-7.

170 Martin-Sanchez G J., Morillas-Marquez F. Pool screen PCR for estimating the prevalence of leishmania infantum infection in sandflies (diptera: Nematocera, phlebotomidae). Trans R Soc Trop Med Hyg 2006; 100: 527-32.

171 Martinez-Hernandez R-F F., Villalobos G. Follow up of natural infection with trypanosoma cruzi in two mammals species, nasua narica and procyon lotor (carnivora: Procyonidae): Evidence of infection control? Parasit Vectors 2014; 7: 405.

172 Mascolli S Roberta, Vasconcellos SA. Prevalence and risk factors for leishmaniasis and chagas disease in the canine population of the tourist city of ibiúna, são paulo, brazil. Semina: Ciências Agrárias 2016; 37: 1971-80.

173 Maslov W D. A., Sturm NR. Discovery and barcoding by analysis of spliced leader RNA gene sequences of new isolates of trypanosomatidae from heteroptera in costa rica and ecuador. J Eukaryot Microbiol 2007; 54: 57-65.

174 Mejia-Jaramillo A-U A. M., Triana-Chavez O. Genotyping of trypanosoma cruzi in a hyper-endemic area of colombia reveals an overlap among domestic and sylvatic cycles of chagas disease. Parasit Vectors 2014; 7: 108.

175 Mekata K H., Ohashi K. Prevalence and source of trypanosome infections in fieldcaptured vector flies (glossina pallidipes) in southeastern zambia. J Vet Med Sci 2008; 70: 923-8.

176 Mekata K H., Ohashi K. Molecular detection of trypanosomes in cattle in south america and genetic diversity of trypanosoma evansi based on expression-site-associated gene 6. Infect Genet Evol 2009; 9: 1301-5. 
177 Mekibib MT B.Manegerew. Prevalence of haemoparasites and associated risk factors in working donkeys in adigudem and kwiha districts of tigray region, northern ethiopia. Journal of Animal and Veterinary Advances 2010; 9: 2249-55.

178 Mekonnen VK B.Regassa. Epidemiology of trypanosomosis in goats in abelti, bede and ghibe valley, south west ethiopia. International Journal of Tropical Medicine 2014; 9: $10-4$.

179 Araujo Melo B de S., Abreu-Silva AL. Bovine trypanosomiasis an emerging disease in maranhao state-brazil. Vector Borne Zoonotic Dis 2011; 11: 853-6.

180 Menezes FE J. A., Margonari C. An integrated approach using spatial analysis to study the risk factors for leishmaniasis in area of recent transmission. Biomed Res Int 2015;

2015: 621854 .

181 Meyers M A. C., Hamer SA. Widespread trypanosoma cruzi infection in government working dogs along the texas-mexico border: Discordant serology, parasite genotyping and associated vectors. PLoS Negl Trop Dis 2017; 11: e0005819.

182 Mihret A, Mamo G. Bovine trypanosomosis in three districts of east gojjam zone bordering the blue nile river in ethiopia. J Infect Dev Ctries 2007; 1: 321-5.

183 Miro C G., Galvez R. Current situation of leishmania infantum infection in shelter dogs in northern spain. Parasit Vectors 2012; 5: 60.

184 Miro M G., Molina R. A leishmaniosis surveillance system among stray dogs in the region of madrid: Ten years of serodiagnosis (1996-2006). Parasitol Res 2007; 101: 253-7.

185 Mohebali H M., Fakhar M. Epidemiological aspects of canine visceral leishmaniosis in the islamic republic of iran. Vet Parasitol 2005; 129: 243-51.

186 Molina R J. M., Gutiérrez C. Seroprevalence of trypanosoma evansi in dromedaries (camelus dromedarius) from the canary islands (spain) using an antibody ab-ELISA. Preventive Veterinary Medicine 2000; 47: 53-9.

187 Monroy R C., Tabaru Y. Epidemiology of chagas disease in guatemala: Infection rate of triatoma dimidiata, triatoma nitida and rhodnius prolixus (hemiptera, reduviidae) with trypanosoma cruzi and trypanosoma rangeli (kinetoplastida, trypanosomatidae). Mem Inst Oswaldo Cruz 2003; 98: 305-10.

188 Morimoto K T., Kadowaki T. Molecular detection of protozoan parasites infecting apis mellifera colonies in japan. Environ Microbiol Rep 2013; 5: 74-7.

189 Muhanguzi M D., Tweyongyere R. African animal trypanosomiasis as a constraint to livestock health and production in karamoja region: A detailed qualitative and quantitative assessment. BMC Vet Res 2017; 13: 355. 
190 Muhanguzi P D., Welburn SC. The burden and spatial distribution of bovine african trypanosomes in small holder crop-livestock production systems in tororo district, southeastern uganda. Parasit Vectors 2014; 7: 603.

191 N'Djetchi I M. K., Jamonneau V. The study of trypanosome species circulating in domestic animals in two human african trypanosomiasis foci of cote d'ivoire identifies pigs and cattle as potential reservoirs of trypanosoma brucei gambiense. PLoS Negl Trop Dis 2017; 11: e0005993.

192 Nakayima N J., Sugimoto C. Molecular epidemiological studies on animal trypanosomiases in ghana. Parasit Vectors 2012; 5: 217.

193 Sachman-Ruiz N-P Bernardo, Reynaud E. Commercial bombus impatiens as reservoirs of emerging infectious diseases in central méxico. Biological Invasions 2015; 17 : 2043-53.

194 Ngaira B J. M., Karanja SM. Animal-level risk factors for trypanosoma evansi infection in camels in eastern and central parts of kenya. Onderstepoort J Vet Res 2002; 69: 263-71.

195 Ngonyoka G A., Cattadori IM. Patterns of tsetse abundance and trypanosome infection rates among habitats of surveyed villages in maasai steppe of northern tanzania. Infect Dis Poverty 2017; 6: 126.

196 Mbang Nguema BA O., Mawili Mboumba DP. Variations of glossina sp. And trypanosome species frequency within different habitats in a sleeping sickness focus, gabon. J Infect Dev Ctries 2019; 13: 67-72.

197 Njiokou N F., Herder S. Domestic animals as potential reservoir hosts of trypanosoma brucei gambiense in sleeping sickness foci in cameroon. Parasite 2010; 17: 61-6.

198 Njiru C Z. K., Reid SA. Detection of trypanosoma evansi in camels using PCR and CATT/t. Evansi tests in kenya. Vet Parasitol 2004; 124: 187-99.

199 Northover G A. S., Thompson RCA. Increased trypanosoma spp. Richness and prevalence of haemoparasite co-infection following translocation. Parasit Vectors 2019; 12: 126.

200 Oakgrove H K. S., Sehgal RN. Distribution, diversity and drivers of blood-borne parasite co-infections in alaskan bird populations. Int J Parasitol 2014; 44: 717-27.

201 Odeniran M P. O., Welburn SC. Molecular identification of bovine trypanosomes in relation to cattle sources in southwest nigeria. Parasitol Int 2019; 68: 1-8.

202 Oliveira P G. C., Langoni H. Antibodies to leishmania spp. In domestic felines. Rev Bras Parasitol Vet 2015; 24: 464-70. 
203 Onyekwelu FEE K. C.Ejezie. Molecular identification of trypanosomes in tsetse flies trapped from onicha ugbo in delta state of nigeria. Biomedical Research-India 2017; 28: 5463-7.

204 Opara BO M. N.Fagbemi. Animal biodiversity and emerging diseases: Prediction and prevention. 2008; 1149: 394-7.

205 Oshaghi R M. A., Rassi Y. Vector incrimination of sand flies in the most important visceral leishmaniasis focus in iran. Am J Trop Med Hyg 2009; 81: 572-7.

206 Otranto N D., Brianti E. Feline and canine leishmaniosis and other vector-borne diseases in the aeolian islands: Pathogen and vector circulation in a confined environment. Vet Parasitol 2017; 236: 144-51.

207 Otranto T D., Breitschwerdt EB. Diagnosis of canine vector-borne diseases in young dogs: A longitudinal study. J Clin Microbiol 2010; 48: 3316-24.

208 Ouedraogo D-U G. M. S., Abd-Alla AMM. Prevalence of trypanosomes, salivary gland hypertrophy virus and wolbachia in wild populations of tsetse flies from west africa. $B M C$ Microbiol 2018; 18: 153.

209 Ozbel O Y., Ozcel MA. A survey on canine leishmaniasis in western turkey by parasite, DNA and antibody detection assays. Acta Trop 2000; 74: 1-6.

210 Paiz F L. M., Langoni H. Serological evidence of infection by leishmania (leishmania) infantum (synonym: Leishmania (leishmania) chagasi) in free-ranging wild mammals in a nonendemic region of the state of sao paulo, brazil. Vector Borne Zoonotic Dis 2015; 15: 667-73.

211 Parashar S R., Bal MS. Unraveling cryptic epizootiology of equid trypanosomosis in punjab state of india by parasitological and sero-molecular techniques. Acta Trop 2018; 185: 18-26.

212 Paz R G. F., Dias ES. Association between the prevalence of infestation by rhipicephalus sanguineus and ctenocephalides felis felis and the presence of antileishmania antibodies: A case-control study in dogs from a brazilian endemic area. Prev Vet Med 2010; 97: 131-3.

213 Plischuk A S., Lange CE. Long-term prevalence of the protists crithidia bombi and apicystis bombi and detection of the microsporidium nosema bombi in invasive bumble bees. Environ Microbiol Rep 2017; 9: 169-73.

214 Popp E M., Lattorff HM. Seasonal variability of prevalence and occurrence of multiple infections shape the population structure of crithidia bombi, an intestinal parasite of bumblebees (bombus spp.). Microbiologyopen 2012; 1: 362-72.

215 Rangel L D. A., Roque ALR. Isolation and characterization of trypanosomatids, including crithidia mellificae, in bats from the atlantic forest of rio de janeiro, brazil. PLoS Negl Trop Dis 2019; 13: e0007527. 
216 Ravel M S., Davoust B. A study on african animal trypanosomosis in four areas of senegal. Folia Parasitol (Praha) 2015; 62. D0I:10.14411/fp.2015.044.

217 Ravoet M J., Graaf DC de. Comprehensive bee pathogen screening in belgium reveals crithidia mellificae as a new contributory factor to winter mortality. PLoS One 2013; 8: e72443.

218 Reid SA, Copeman DB. Surveys in papua new guinea to detect the presence of trypanosoma evansi infection. Aust Vet J 2000; 78: 843-5.

219 Reithinger E R., Davies CR. Evaluation of PCR as a diagnostic mass-screening tool to detect leishmania (viannia) spp. In domestic dogs (canis familiaris). J Clin Microbiol 2003; 41: 1486-93.

220 Reithinger BEB R.Lambson. Use of PCR to detect leishmania (viannia) spp. In dog blood and bone marrow. Journal of Clinical Microbiology 2000; 38: 748-51.

221 Resadore J F., Medeiros JF. Composition and vertical stratification of phlebotomine sand fly fauna and the molecular detection of leishmania in forested areas in rondonia state municipalities, western amazon, brazil. Vector Borne Zoonotic Dis 2019; 19: 347-57.

222 Ribeiro M A. R., Rosa JA da. Trypanosoma cruzi strains from triatomine collected in bahia and rio grande do sul, brazil. Rev Saude Publica 2014; 48: 295-302.

223 Rocha M Avvo, Costa APD. Diagnosis and epidemiology of leishmania infantum in domestic cats in an endemic area of the amazon region, brazil. Vet Parasitol 2019; 273: 805 .

224 Rodrigues S A. C., Bevilaqua CM. Epidemiological survey of lutzomyia longipalpis infected by leishmania infantum in an endemic area of brazil. Rev Bras Parasitol Vet 2014; 23: $55-62$.

225 Rodriguez T-J N. F., Gutierrez C. Cross-sectional study on prevalence of trypanosoma evansi infection in domestic ruminants in an endemic area of the canary islands (spain). Prev Vet Med 2012; 105: 144-8.

226 Rohousova T-F I., Baneth G. Exposure to leishmania spp. And sand flies in domestic animals in northwestern ethiopia. Parasit Vectors 2015; 8: 360.

227 Rondon B F. C., Diniz AT. Cross-sectional serological study of canine leishmania infection in fortaleza, ceara state, brazil. Vet Parasitol 2008; 155: 24-31.

228 Rowland M M. E., Moncayo AC. Factors associated with trypanosoma cruzi exposure among domestic canines in tennessee. J Parasitol 2010; 96: 547-51.

229 Saghafipour V A., Hanafi-Bojd AA. Epidemiological study on cutaneous leishmaniasis in an endemic area, of qom province, central iran. J Arthropod Borne Dis 2017; 11: 403-13.

230 Salim B B., Sugimoto C. Molecular epidemiology of camel trypanosomiasis based on ITS1 rDNA and RoTat 1.2 VSG gene in the sudan. Parasit Vectors 2011; 4: 31. 
231 Salim B B., Sugimoto C. Molecular detection of equine trypanosomes in the sudan. Vet Parasitol 2014; 200: 246-50.

232 Santos G Helcileia Dias, Minharro S. High frequency of visceral leishmaniasis in dogs under veterinary clinical care in an intense transmission area in the state of tocantins, brazil. Ciência Rural 2017; 47. DOI:10.1590/0103-8478cr20160260.

233 Saraiva L L., Andrade JDF. Seasonality of sand flies (diptera: Psychodidae) and leishmania DNA detection in vector species in an area with endemic visceral leishmaniasis. Mem Inst Oswaldo Cruz 2017; 112: 309-18.

234 Sarquis B-P 0., Lima MM. Epidemiology of chagas disease in jaguaruana, ceara, brazil. I. Presence of triatomines and index of trypanosoma cruzi infection in four localities of a rural area. Mem Inst Oswaldo Cruz 2004; 99: 263-70.

235 Sauda M F., Perrucci S. Leishmania infantum, dirofilaria spp. And other endoparasite infections in kennel dogs in central italy. Parasite 2018; 25: 2.

236 Savage R A. F., Greiner EC. Blood parasites in birds from madagascar. J Wildl Dis 2009; 45: 907-20.

237 Schoener U E., Fuehrer HP. Trypanosomatid parasites in austrian mosquitoes. PLoS One 2018; 13: e0196052.

238 Schultz U Albert, Underhill G. Infection prevalence and absence of positive correlation between avian haemosporidian parasites, mass and body condition in the cape weaver ploceus capensis. Ostrich 2010; 81: 69-76.

239 Sebaio B Fabiane, Marini MÂn. Blood parasites in brazilian atlantic forest birds: Effects of fragment size and habitat dependency. Bird Conservation International 2010; 20: 432-9.

240 Sebaio B F., Marini MA. Blood parasites in passerine birds from the brazilian atlantic forest. Rev Bras Parasitol Vet 2012; 21: 7-15.

241 Seck B M. T., Vreysen MJ. The prevalence of african animal trypanosomoses and tsetse presence in western senegal. Parasite 2010; 17: 257-65.

242 Sehgal J R. N., Smith TB. Host specificity and incidence of trypanosoma in some african rainforest birds: A molecular approach. Mol Ecol 2001; 10: 2319-27.

243 Shahzad M W., Iqbal M. Prevalence and molecular diagnosis of trypanosoma evansi in nili-ravi buffalo (bubalus bubalis) in different districts of punjab (pakistan). Trop Anim Health Prod 2010; 42: 1597-9.

244 Sharma DS A., Juyal PD. Molecular prevalence of babesia bigemina and trypanosoma evansi in dairy animals from punjab, india, by duplex PCR: A step forward to the detection and management of concurrent latent infections. Biomed Res Int 2013; 2013: 893862. 
245 Sharma J P., Pawar H. Comparative evaluation of real time PCR assay with conventional parasitological techniques for diagnosis of trypanosoma evansi in cattle and buffaloes. Vet Parasitol 2012; 190: 375-82.

246 Sheferaw B D., Woldesenbet Z. Bovine trypanosomosis and glossina distribution in selected areas of southern part of rift valley, ethiopia. Acta Trop 2016; 154: 145-8.

247 Shereni A W., Cecchi G. Spatial distribution and trypanosome infection of tsetse flies in the sleeping sickness focus of zimbabwe in hurungwe district. Parasit Vectors 2016; 9: 605.

248 Silva P R. B. S., Melo MA. Seroprevalence and risk factors associated with canine visceral leishmaniasis in the state of paraiba, brazil. Rev Soc Bras Med Trop 2018; 51: 6838.

249 Simo S G., Asonganyi T. Identification and genetic characterization of trypanosoma congolense in domestic animals of fontem in the south-west region of cameroon. Infect Genet Evol 2013; 18: 66-73.

250 Simukoko M H., Van den Bossche P. The comparative role of cattle, goats and pigs in the epidemiology of livestock trypanosomiasis on the plateau of eastern zambia. Vet Parasitol 2007; 147: 231-8.

251 Simwango N M., Gwakisa PS. Molecular prevalence of trypanosome infections in cattle and tsetse flies in the maasai steppe, northern tanzania. Parasit Vectors 2017; 10: 507.

252 Singh AKS A. P.Tripathi. Seroprevalence of trypanosoma evansi in buffaloes in south western semiarid plane zone of uttarpradesh. Buffalo Bulletin 2017; 36: 483-8.

253 Sinshaw A A., Yoni W. Biting flies and trypanosoma vivax infection in three highland districts bordering lake tana, ethiopia. Vet Parasitol 2006; 142: 35-46.

254 Sousa L S., Cordeiro da Silva A. Seroepidemiological survey of leishmania infantum infection in dogs from northeastern portugal. Acta Trop 2011; 120: 82-7.

255 Specht EJ. Prevalence of bovine trypanosomosis in central mozambique from 2002 to 2005. Onderstepoort J Vet Res 2008; 75: 73-81.

256 Suh N P. F., Garabed R. Bovine trypanosomiasis in tsetse-free pastoral zone of the far-north region, cameroon. J Vector Borne Dis 2017; 54: 263-9.

257 Svobodova V M., Votypka J. Trypanosomatids in ornithophilic bloodsucking diptera. Med Vet Entomol 2015; 29: 444-7.

258 Takeet F M. I., Imumorin IG. Molecular survey of pathogenic trypanosomes in naturally infected nigerian cattle. Res Vet Sci 2013; 94: 555-61.

259 Tasew R S.Duguma. Cattle anaemia and trypanosomiasis in western oromia state, ethiopia. Revue De Medecine Veterinaire 2012; 163: 581-8. 
260 Tatard G C., Dobigny G. Rodent-borne trypanosoma from cities and villages of niger and nigeria: A special role for the invasive genus rattus? Acta Trop 2017; 171: 151-8.

261 Tehseen J S., Buscher P. Parasitological, serological and molecular survey of trypanosoma evansi infection in dromedary camels from cholistan desert, pakistan. Parasit Vectors 2015; 8: 415.

262 Teles S C. B., Camargo LM. Phlebotomine sandfly (diptera: Psychodidae) diversity and their leishmania DNA in a hot spot of american cutaneous leishmaniasis human cases along the brazilian border with peru and bolivia. Mem Inst Oswaldo Cruz 2016; 0: 0.

263 Terefe H E., Mwai O. Phenotypic characteristics and trypanosome prevalence of mursi cattle breed in the bodi and mursi districts of south omo zone, southwest ethiopia. Trop Anim Health Prod 2015; 47: 485-93.

264 Thies R S. F., Dias ES. Phlebotomine sandfly fauna and natural leishmania infection rates in a rural area of cerrado (tropical savannah) in nova mutum, state of mato grosso in brazil. Rev Soc Bras Med Trop 2013; 46: 293-8.

265 Tiwary K P., Sundar S. Prevalence of sand flies and leishmania donovani infection in a natural population of female phlebotomus argentipes in bihar state, india. Vector Borne Zoonotic Dis 2012; 12: 467-72.

266 Tognazzo S-H M., Schmid-Hempel P. Probing mixed-genotype infections II: High multiplicity in natural infections of the trypanosomatid, crithidia bombi, in its host, bombus spp. PLoS One 2012; 7: e49137.

267 Tripodi C-S Amber D., Szalanski AL. Nosema bombi(microsporidia: Nosematidae) and trypanosomatid prevalence in spring bumble bee queens (hymenoptera: Apidae:bombus) in kansas. Journal of the Kansas Entomological Society 2014; 87: 225-33.

268 Tripodi S A. D., Strange JP. Novel multiplex PCR reveals multiple trypanosomatid species infecting north american bumble bees (hymenoptera: Apidae: bombus). J Invertebr Pathol 2018; 153: 147-55.

269 Vanderplanck R Maryse, Michez D. Bumble bee parasite prevalence but not genetic diversity impacted by the invasive plant impatiens glandulifera. Ecosphere 2019; 10. DOI:10.1002/ecs2.2804.

270 Vavilova K V. Y., Blinov AG. Parasites of the genus nosema, crithidia and lotmaria in the honeybee and bumblebee populations: A case study in india. Vavilov Journal of Genetics and Breeding 2017; 21: 943-51.

271 Villagran M M. E., Diego JA de. Natural infection and distribution of triatomines (hemiptera: Reduviidae) in the state of queretaro, mexico. Trans R Soc Trop Med Hyg 2008; 102: 833-8.

272 Votypka K J., Lukes J. High prevalence and endemism of trypanosomatids on a small caribbean island. J Eukaryot Microbiol 2019; 66: 600-7. 
273 Votypka M J., Lukes J. Probing into the diversity of trypanosomatid flagellates parasitizing insect hosts in south-west china reveals both endemism and global dispersal. Mol Phylogenet Evol 2010; 54: 243-53.

274 Votypka S J., Yurchenko V. Diversity of trypanosomatids (kinetoplastea:

Trypanosomatidae) parasitizing fleas (insecta: Siphonaptera) and description of a new genus blechomonas gen. n. Protist 2013; 164: 763-81.

275 Waiswa O-M C., Katunguka-Rwakishaya E. Domestic animals as reservoirs for sleeping sickness in three endemic foci in south-eastern uganda. Ann Trop Med Parasitol 2003; 97: 149-55.

276 Weber N J. S., Kelm S. Genetic diversity of trypanosome species in tsetse flies (glossina spp.) In nigeria. Parasit Vectors 2019; 12: 481.

277 Wei S F., Liu Q. Molecular detection and genetic diversity of leishmania donovani in naturally infected phlebotomus chinensi from southwestern china. Vector Borne Zoonotic Dis 2011; 11: 849-52.

278 Whitehorn T P. R., Goulson D. Genetic diversity, parasite prevalence and immunity in wild bumblebees. Proc Biol Sci 2011; 278: 1195-202.

279 Whitehorn T Penelope R., Goulson D. Investigating the impact of deploying commercial bombus terrestris for crop pollination on pathogen dynamics in wild bumble bees. Journal of Apicultural Research 2015; 52: 149-57.

280 Wilfert L L., Jiggins FM. Trypanosomatids are common and diverse parasites of drosophila. Parasitology 2011; 138: 858-65.

281 Xu P-Y G., Rich S. Triplex real-time PCR for detection of crithidia mellificae and lotmaria passim in honey bees. Parasitol Res 2018; 117: 623-8.

282 Yadav K S. C., Kumar R. Seroprevalence of trypanosoma evansi infection in equines of north and north western states of india. J Equine Vet Sci 2019; 79: 63-7.

283 Zorrilla DLS V., Valdivia HO. Distribution and identification of sand flies naturally infected with leishmania from the southeastern peruvian amazon. PLoS Negl Trop Dis 2017; 11: e0006029.

284 Abbaszadeh Afshar S M. J., Naderi A. Canine visceral leishmaniasis; a seroepidemiological survey in jiroft district, southern kerman province, southeastern iran in 2015. Iran J Parasitol 2018; 13: 67-71.

285 Abdeen S Z. A., Baneth G. Epidemiology of visceral leishmaniasis in the jenin district, west bank: 1989-1998. Am J Trop Med Hyg 2002; 66: 329-33.

286 Abebe R, Wolde A. A cross-sectional study of trypanosomosis and its vectors in donkeys and mules in northwest ethiopia. Parasitol Res 2010; 106: 911-6. 
287 Abrantes MM T. R., Figueiredo FB. Identification of canine visceral leishmaniasis in a previously unaffected area by conventional diagnostic techniques and cell-block fixation. Rev Inst Med Trop Sao Paulo 2016; 58: 3.

288 Abrantes W T. R., Figueiredo FB. Environmental factors associated with canine visceral leishmaniasis in an area with recent introduction of the disease in the state of rio de janeiro, brazil. Cad Saude Publica 2018; 34: e00021117.

289 Akhavan Y-E A., Khamesipour A. Molecular epizootiology of rodent leishmaniasis in a hyperendemic area of iran. Iran J Public Health 2010; 39: 1-7.

290 Akhtardanesh S B., Pourafshar NG. Feline visceral leishmaniasis in kerman, southeast of iran: Serological and molecular study. J Vector Borne Dis 2017; 54: 96-102.

291 Akinpelu AI. Prevalence and intensity of blood parasites in wild pigeons and doves (family: Columbidae) from shasha forest reserve, ile-ife, nigeria. Asian Journal of Animal and Veterinary Advances 2008; 3: 109-14.

292 Akter A S., Katakura K. Molecular and serological evidence of leishmania infection in stray dogs from visceral leishmaniasis-endemic areas of bangladesh. Am J Trop Med Hyg 2016; 95: 795-9.

293 Albuquerque C A., Cortes S. Evaluation of four molecular methods to detect leishmania infection in dogs. Parasit Vectors 2017; 10: 57.

294 Alho P A. M., Carvalho LM de. Seroprevalence of vector-borne pathogens and molecular detection of borrelia afzelii in military dogs from portugal. Parasit Vectors 2016; 9: 225 .

295 Almeida F C. E., Harry M. Molecular individual-based approach on triatoma brasiliensis: Inferences on triatomine foci, trypanosoma cruzi natural infection prevalence, parasite diversity and feeding sources. PLoS Negl Trop Dis 2016; 10: e0004447.

296 Alroy H K. A., Working Group on Chagas Disease in P. Prevalence and transmission of trypanosoma cruzi in people of rural communities of the high jungle of northern peru. PLoS Negl Trop Dis 2015; 9: e0003779.

297 Alvasen J K., Emanuelson U. A field survey on parasites and antibodies against selected pathogens in owned dogs in lilongwe, malawi. J S Afr Vet Assoc 2016; 87: e1-6.

298 Leite Rabelo T Elida Mara, Bhering LL. Comparison of three methods for diagnosis of trypanosoma (duttonella) vivax in cattle. Genetics and Molecular Research 2017; 16. DOI:10.4238/gmr16039811.

299 Amer R S., Nakai Y. Molecular identification and phylogenetic analysis of trypanosoma evansi from dromedary camels (camelus dromedarius) in egypt, a pilot study. Acta Trop 2011; 117: 39-46. 
300 Amiri Ghannat Saman D I., Pirestani M. Biodiversity, leishmania genetic typing and host identification of phlebotomine species in endemic foci of southeastern iran. Heliyon 2019; 5: e02369.

301 Antonio M E. G., Machado-Coelho GL. Canine visceral leishmaniasis in the krenak indigenous community, resplendor, minas gerais state, brazil, 2007. Cad Saude Publica 2011; 27: 603-7.

302 Aragort A W., Sanmartin ML. Blood protozoans in elasmobranchs of the family rajidae from galicia (NW spain). Dis Aquat Organ 2005; 65: 63-8.

303 Arce-Fonseca C-S M., Rodriguez-Morales O. Seropositivity for trypanosoma cruzi in domestic dogs from sonora, mexico. Infect Dis Poverty 2017; 6: 120.

304 Cruz B SM Luis, Arjona J G. Anticuerpos de trypanosoma cruzi, leishmania mexicana y leishmania braziliensis en perros domiciliados de tabasco, méxico. Revista MVZ Córdoba 2017; 22: 5829-36.

305 Aslantas 0 0., Babur C. Seroepidemiology of leptospirosis, toxoplasmosis, and leishmaniosis among dogs in ankara, turkey. Vet Parasitol 2005; 129: 187-91.

306 Attipa P C., Tasker S. Prevalence study and risk factor analysis of selected bacterial, protozoal and viral, including vector-borne, pathogens in cats from cyprus. Parasit Vectors 2017; 10: 130.

307 Austen 0 J. M., Ryan U. High prevalence of trypanosoma vegrandis in bats from western australia. Vet Parasitol 2015; 214: 342-7.

308 Azeem T Tamoor, Umar S. Hematobiochemical disorder in camels suffering from different hemoparasites. Pakistan Journal of Zoology 2019; 51: 591-6.

309 Azpurua DLC J., Windsor D. Lutzomyia sand fly diversity and rates of infection by wolbachia and an exotic leishmania species on barro colorado island, panama. PLoS Negl Trop Dis 2010; 4: e627.

310 Bakirci B Serkan, KaragenÇ T. Molecular and seroprevalence of canine visceral leishmaniasis in west anatolia, turkey. Turkish Journal of Veterinary and Animal Sciences 2016; 40: 637-44.

311 Bamorovat S M., Aflatoonian MR. Canine visceral leishmaniasis in kerman, southeast of iran: A seroepidemiological, histopathological and molecular study. Iran J Parasitol 2014; 9: 342-9.

312 Bar ME, Wisnivesky-Colli C. Triatoma sordida stal 1859 (hemiptera, reduviidae: Triatominae) in palms of northeastern argentina. Mem Inst Oswaldo Cruz 2001; 96: 895-9.

313 Barbosa A A., Ryan U. First report of trypanosoma vegrandis in koalas (phascolarctos cinereus). Parasitol Int 2016; 65: 316-8. 
314 Barbosa G A. D., Ryan U. Increased genetic diversity and prevalence of co-infection with trypanosoma spp. In koalas (phascolarctos cinereus) and their ticks identified using next-generation sequencing (NGS). PLoS One 2017; 12: e0181279.

315 Barbosa R A., Ryan U. Prevalence, genetic diversity and potential clinical impact of blood-borne and enteric protozoan parasites in native mammals from northern australia. Vet Parasitol 2017; 238: 94-105.

316 Barnard M-H William H., Matsuoka SM. Prevalence of hematozoa infections among breeding and wintering rusty blackbirds. The Condor 2010; 112: 849-53.

317 Barros X J. H. S., Jansen AM. Identification of novel mammalian hosts and brazilian biome geographic distribution of trypanosoma cruzi TcIII and TcIV. Acta Trop 2017; 172: 173-9.

318 Ben Othman G S., Ben Abderrazak S. First detection of leishmania DNA in psammomys obesus and psammomys vexillaris: Their potential involvement in the epidemiology of leishmaniasis in tunisia. Infect Genet Evol 2018; 59: 7-15.

319 Benassi B J. C., Oliveira T. Detection of leishmania infantum DNA in conjunctival swabs of cats by quantitative real-time PCR. Exp Parasitol 2017; 177: 93-7.

320 Berger W R., Kotler BP. Zoonotic disease in a peripheral population: Persistence and transmission of leishmania major in a putative sink-source system in the negev highlands, israel. Vector Borne Zoonotic Dis 2014; 14: 592-600.

321 Bhattarai D N. R., Van der Auwera G. Development and evaluation of different PCRbased typing methods for discrimination of leishmania donovani isolates from nepal. Parasitology 2010; 137: 947-57.

322 Bhutto JAS B.Gadahi. Field investigation on the prevalence of trypanosomiasis in camels in relation to sex, age, breed and herd size. Pakistan Veterinary Journal 2010; 30: 175-7.

323 Bigeli O J. G., Teles NM. Diagnosis of leishmania (leishmania) chagasi infection in dogs and the relationship with environmental and sanitary aspects in the municipality of palmas, state of tocantins, brazil. Rev Soc Bras Med Trop 2012; 45: 18-23.

324 Bilgin NY Z.Turan. Prevalence of leishmaniosis in dogs in istanbul, turkey determined by using PCR. Journal of the Hellenic Veterinary Medical Society 2015; 66: 10612 .

325 Bitew YA M.Amedie. Prevalence of bovine trypanosomosis in selected areas of jabi tehenan district, west gojam of amhara regional state, northwestern ethiopia. African Journal of Agricultural Research 2011; 6: 140-4.

326 Bolukbas GZG C. S.Pekmezci. Evidence of leishmania spp. Antibodies and DNA in dogs in the middle black sea region of turkey. Ankara Universitesi Veteriner Fakultesi Dergisi 2016; 63: 111-4. 
327 Borji GP H.Razmi. Epidemiological study on haemoparasites of dromedary (camelus dromedarius) in iran. Journal of Camel Practice and Research 2009; 16: 217-9.

328 Botto-Mahan B C., Solari A. Field assessment of trypanosoma cruzi infection and host survival in the native rodent octodon degus. Acta Trop 2012; 122: 164-7.

329 Brasil M Arthur Willian de Lima, Azevedo SS de. Prevalence and risk factors associated with leishmania spp. And trypanosoma cruzi infections in dogs presented at veterinary clinics in joão pessoa, paraíba state, northeastern brazil. Semina: Ciências Agrárias 2018; 39: 2293-300.

330 Bray B D. P., Birtles RJ. Haemoparasites of common shrews (sorex araneus) in northwest england. Parasitology 2007; 134: 819-26.

331 Breniere A S. F., Noireau F. Genetic characterization of trypanosoma cruzi DTUs in wild triatoma infestans from bolivia: Predominance of TcI. PLoS Negl Trop Dis 2012; 6: e1650.

332 Brigada D A. M., Basso B. American tripanosomiasis: A study on the prevalence of trypanosoma cruzi and trypanosoma cruzi-like organisms in wild rodents in san luis province, argentina. Rev Soc Bras Med Trop 2010; 43: 249-53.

333 Brito L F. G., Paz GS. Canine visceral leishmaniasis in the northeast region of brazil. J Venom Anim Toxins Incl Trop Dis 2016; 22: 15.

334 Brown R E. L., Yabsley MJ. Seroprevalence of trypanosoma cruzi among eleven potential reservoir species from six states across the southern united states. Vector Borne Zoonotic Dis 2010; 10: 757-63.

335 Buhaya G M. H., Maldonado RA. Incidence of trypanosoma cruzi infection in triatomines collected at indio mountains research station. Acta Trop 2015; 150: 97-9.

336 Bustamante DU-S D. M., Pennington PM. Ecological, social and biological risk factors for continued trypanosoma cruzi transmission by triatoma dimidiata in guatemala. PLoS One 2014; 9: e104599.

337 Cai W Y., Zhang X. First report of the prevalence and genotype of trypanosoma spp. In bats in yunnan province, southwestern china. Acta Trop 2019; 198: 105105.

338 Caldart C Eloiza Teles, Freire RL. Zoonosis in dogs and cats attended by the birth control project: Toxoplasma gondii, leishmania spp. And leptospira spp., Serodiagnosis and epidemiology. Semina: Ciências Agrárias 2015; 36: 253-65.

339 Caldart F E. T., Navarro IT. Leishmania in synanthropic rodents (rattus rattus): New evidence for the urbanization of leishmania (leishmania) amazonensis. Rev Bras Parasitol Vet 2017; 26: 17-27.

340 Calzada S J. E., Chaves LF. Cutaneous leishmaniasis in dogs: Is high seroprevalence indicative of a reservoir role? Parasitology 2015; 142: 1202-14. 
341 Camejo PMG M. I.Aso. Relationship between asymptomatic infections with anaplasma marginale, babesia spp. And trypanosoma vivax in bulls and testosterone levels. Revista Cientifica-Facultad De Ciencias Veterinarias 2016; 26: 13-9.

342 Cardoso G L., Baneth G. First report of anaplasma platys infection in red foxes (vulpes vulpes) and molecular detection of ehrlichia canis and leishmania infantum in foxes from portugal. Parasit Vectors 2015; 8: 144.

343 Cardoso L L., Solano-Gallego L. Low seroprevalence of leishmania infantum infection in cats from northern portugal based on DAT and ELISA. Vet Parasitol 2010; 174: 37-42.

344 Castro B J. C., Barcante JMP. Molecular detection of leishmania spp in lutzomyia longipalpis in the city of lavras, minas gerais, brazil. Braz J Med Biol Res 2019; 52: e8224.

345 Chargui S N., Babba H. Transmission cycle analysis in a leishmania infantum focus: Infection rates and blood meal origins in sand flies (diptera: psychodidae). J Vector Ecol 2018; 43: 321-7.

346 Charles K R. A., Yabsley MJ. Southern plains woodrats (neotoma micropus) from southern texas are important reservoirs of two genotypes of trypanosoma cruzi and host of a putative novel trypanosoma species. Vector Borne Zoonotic Dis 2013; 13: 22-30.

347 Chatzis A M. K., Saridomichelakis MN. Cytological and molecular detection of leishmania infantum in different tissues of clinically normal and sick cats. Vet Parasitol 2014; 202: 217-25.

348 Chaudhary ZI, Iqbal J. Incidence, biochemical and haematological alterations induced by natural trypanosomosis in racing dromedary camels. Acta Trop 2000; 77: 20913.

349 Chaudhry AA Z. I.JahanzaibAslam. Prevalence of trypanosoma evansi in camels through polymerase chain reaction and haematocrit centrifugation technique in punjab (pakistan). Journal of Camel Practice and Research 2008; 15: 183-5.

350 Chen L H., Chen J. Multi-locus characterization and phylogenetic inference of leishmania spp. In snakes from northwest china. PLoS One 2019; 14: e0210681.

351 Cherenet S T., Van den Bossche P. A comparative longitudinal study of bovine trypanosomiasis in tsetse-free and tsetse-infested zones of the amhara region, northwest ethiopia. Vet Parasitol 2006; 140: 251-8.

352 Chitimia M-G L., Berriatua E. Cryptic leishmaniosis by leishmania infantum, a feature of canines only? A study of natural infection in wild rabbits, humans and dogs in southeastern spain. Vet Parasitol 2011; 181: 12-6.

353 Concannon W-O R., Birtles RJ. Molecular characterization of haemoparasites infecting bats (microchiroptera) in cornwall, UK. Parasitology 2005; 131: 489-96. 
354 Constantino P Caroline, Navarro IT. Seroepidemiology of leishmania spp. In dogs residing in telêmaco borba, paraná, brazil. Semina: Ciências Agrárias 2014; 35: 3181-90.

355 Coronado R X., Solari A. Molecular epidemiology of chagas disease in the wild transmission cycle: The evaluation in the sylvatic vector mepraia spinolai from an endemic area of chile. Am J Trop Med Hyg 2009; 81: 656-9.

356 Cortada D V. M., Goncalves da Costa SC. Canine visceral leishmaniosis in anastacio, mato grosso do sul state, brazil. Vet Res Commun 2004; 28: 365-74.

357 Cortez V A. P., Teixeira MM. The taxonomic and phylogenetic relationships of trypanosoma vivax from south america and africa. Parasitology 2006; 133: 159-69.

358 Coulibaly T C. A., Doumbia S. Impact of insecticide-treated bednets and indoor residual spraying in controlling populations of phlebotomus duboscqi, the vector of leishmania major in central mali. Parasit Vectors 2018; 11: 345.

359 Couto L C. G., Ruano R. Serological study of selected vector-borne diseases in shelter dogs in central spain using point-of-care assays. Vector Borne Zoonotic Dis 2010; 10: 885-8.

360 Cuba A-F C. A., Miles MA. The triatomines of northern peru, with emphasis on the ecology and infection by trypanosomes of rhodnius ecuadoriensis (triatominae). Mem Inst Oswaldo Cruz 2002; 97: 175-83.

361 Curi M N. H., Talamoni SA. Serologic evidence of leishmania infection in free-ranging wild and domestic canids around a brazilian national park. Mem Inst Oswaldo Cruz 2006; 101: 99-101.

362 Curtis-Robles Z R., Hamer SA. Trypanosoma cruzi (agent of chagas disease) in sympatric human and dog populations in "colonias" of the lower rio grande valley of texas. Am J Trop Med Hyg 2017; 96: 805-14.

363 Costa C Letícia Da, Freire RL. Leishmaniasis in dogs from recycling centers and from a neighborhood with adjacent forest in an urban area of londrina, paraná, brazil. Semina: Ciências Agrárias 2016; 37: 1407-14.

364 Dantas-Torres de P-C F., Brandao-Filho SP. Cutaneous and visceral leishmaniasis in dogs from a rural community in northeastern brazil. Vet Parasitol 2010; 170: 313-7.

365 Dario L M. A., Jansen AM. High trypanosoma spp. Diversity is maintained by bats and triatomines in espirito santo state, brazil. PLoS One 2017; 12: e0188412.

366 Davami M M. H., Pourahmad M. Molecular survey on detection of leishmania infection in rodent reservoirs in jahrom district, southern iran. J Arthropod Borne Dis 2014; 8: $139-46$.

367 Dayo B G. K., Thevenon S. Prevalence and incidence of bovine trypanosomosis in an agro-pastoral area of southwestern burkina faso. Res Vet Sci 2010; 88: 470-7. 
368 Curi P N. H., Chiarello AG. Factors associated with the seroprevalence of leishmaniasis in dogs living around atlantic forest fragments. PLoS One 2014; 9: e104003.

369 Carvalho V de M. R., Brandao Filho SP. Natural leishmania infantum infection in migonemyia migonei (franca, 1920) (diptera:psychodidae:phlebotominae) the putative vector of visceral leishmaniasis in pernambuco state, brazil. Acta Trop 2010; 116: 108-10.

370 Lima G J. T., Soares RM. Serodiagnosis of visceral and cutaneous leishmaniasis in human and canine populations living in indigenous reserves in the brazilian amazon region. Rev Soc Bras Med Trop 2017; 50: 61-6.

371 Mendonca B de I. L., Alves LC. Leishmania (infantum) chagasi in canine urinary sediment. Rev Bras Parasitol Vet 2015; 24: 92-4.

372 Oliveira C E. F., Galati EA. Leishmania amazonensis DNA in wild females of lutzomyia cruzi (diptera: Psychodidae) in the state of mato grosso do sul, brazil. Mem Inst Oswaldo Cruz 2015; 110: 1051-7.

373 Oliveira A L. C., Mendonca-Lima FW. Seroprevalence and risk factors for canine visceral leishmaniasis in the endemic area of dias d'avila, state of bahia, brazil. Rev Soc Bras Med Trop 2010; 43: 400-4.

374 Oliveira G Patrícia Magalhães de, Saut JPE. Seroepidemiology ofLeishmaniaspp. In equids from uberlândia, minas gerais, brazil. Ciência Rural 2017; 47. DOI:10.1590/01038478 cr20160697.

375 Padua I de S. B., Pilarski F. First record of trypanosoma sp. (Protozoa: Kinetoplastida) in tuvira (gymnotus aff. Inaequilabiatus) in the pantanal wetland, mato grosso do sul state, brazil. Rev Bras Parasitol Vet 2011; 20: 85-7.

376 Seabra P de N. M., Oliveira TM. Toxoplasma gondii, neospora caninum and leishmania spp. Serology and leishmania spp. PCR in dogs from pirassununga, SP. Rev Bras Parasitol Vet 2015; 24: 454-8.

377 Sousa H K. C., Andre MR. Serological detection of toxoplasma gondii, leishmania infantum and neospora caninum in cats from an area endemic for leishmaniasis in brazil. Rev Bras Parasitol Vet 2014; 23: 449-55.

378 Deiró M Ana Graziela De Jesus, Albuquerque GR. Antibody occurrence of antitoxoplasma gondii, leishmania sp. And ehrlichia canis in dogs in bahia state. Semina: Ciências Agrárias 2018; 39: 199-210.

379 Demir S, Karakus M. Natural leishmania infection of phlebotomus sergenti (diptera: Phlebotominae) in an endemic focus of cutaneous leishmaniasis in sanliurfa, turkey. Acta Trop 2015; 149: 45-8.

380 Deviche G P., Manteca X. Interspecific variability of prevalence in blood parasites of adult passerine birds during the breeding season in alaska. J Wildl Dis 2001; 37: 28-35. 
381 Dia ML. Parasites of the camel in burkina faso. Trop Anim Health Prod 2006; 38: 1721.

382 Diakou P A., Lazarides K. Specific anti-leishmania spp. Antibodies in stray cats in greece. J Feline Med Surg 2009; 11: 728-30.

383 Diaz-Saez M-E V., Martin-Sanchez J. High rates of leishmania infantum and trypanosoma nabiasi infection in wild rabbits (oryctolagus cuniculus) in sympatric and syntrophic conditions in an endemic canine leishmaniasis area: Epidemiological consequences. Vet Parasitol 2014; 202: 119-27.

384 Dogan O N., Bor O. Sero-epidemological survey on canine visceral leishmaniasis and the distribution of sandfly vectors in northwestern turkey: Prevention strategies for childhood visceral leishmaniasis. J Trop Pediatr 2006; 52: 212-7.

385 Dos Santos L F. C. B., Jansen AM. Trypanosoma sp. Diversity in amazonian bats (chiroptera; mammalia) from acre state, brazil. Parasitology 2018; 145: 828-37.

386 Duarte C A., Vaz Y. Survey of infectious and parasitic diseases in stray cats at the lisbon metropolitan area, portugal. J Feline Med Surg 2010; 12: 441-6.

387 Dumitrache N-B M. O., Baneth G. The quest for canine leishmaniasis in romania: The presence of an autochthonous focus with subclinical infections in an area where disease occurred. Parasit Vectors 2016; 9: 297.

388 Durrani B A. Z., Azeem M. Use of physiological biomarkers in diagnosis along with field trials of different trypanisidal drugs in camels of cholistan desert. Microb Pathog 2017; 108: $1-5$.

389 Ebani P V. V., Mancianti F. Serological survey on some pathogens in wild brown hares (lepus europaeus) in central italy. Asian Pac J Trop Med 2016; 9: 465-9.

390 Echchakery C M., Boumezzough A. Molecular detection of leishmania infantum and leishmania tropica in rodent species from endemic cutaneous leishmaniasis areas in morocco. Parasit Vectors 2017; 10: 454.

391 Echeverria S J. T., Borges FA. Clinical and therapeutic aspects of an outbreak of canine trypanosomiasis. Rev Bras Parasitol Vet 2019; 28: 320-4.

392 Elhaig MM, Sallam NH. Molecular survey and characterization of trypanosoma evansi in naturally infected camels with suspicion of a trypanozoon infection in horses by molecular detection in egypt. Microb Pathog 2018; 123: 201-5.

393 Estrada-Franco B J. G., Garg N. Human trypanosoma cruzi infection and seropositivity in dogs, mexico. Emerg Infect Dis 2006; 12: 624-30.

394 Fallah MR E.Khanmohammadi. Serological survey and comparison of two polymerase chain reaction (PCR) assays with enzyme-linked immunosorbent assay (ELISA) 
for the diagnosis of canine visceral leishmaniasis in dogs. African Journal of Biotechnology 2011; 10: 648-56.

395 Faye B B., Gaye 0. Seroprevalence of leishmania infantum in a rural area of senegal: Analysis of risk factors involved in transmission to humans. Trans R Soc Trop Med Hyg 2011; 105: 333-40.

396 Faye P de A D., Geerts S. Prevalence and incidence of trypanosomosis in horses and donkeys in the gambia. Vet Parasitol 2001; 101: 101-14.

397 Fereig M R. M., Nishikawa Y. Seroprevalence of babesia bovis, b. Bigemina, trypanosoma evansi, and anaplasma marginale antibodies in cattle in southern egypt. Ticks Tick Borne Dis 2017; 8: 125-31.

398 Fernandes C Annielle Regina da Fonseca, Azevedo SS. Occurrence and risk factors of zoonoses in dogs and owners in sertão, paraíba state, northeastern brazil. Semina: Ciências Agrárias 2018; 39: 1057-65.

399 Ferreira Ede C C., Gontijo CM. Mixed infection of leishmania infantum and leishmania braziliensis in rodents from endemic urban area of the new world. BMC Vet Res 2015; $11: 71$.

400 Castro Ferreira P de E., Gontijo CMF. Leishmania (v.) Braziliensis infecting bats from pantanal wetland, brazil: First records for platyrrhinus lineatus and artibeus planirostris. Acta Trop 2017; 172: 217-22.

401 Ferreira C R. T. B., Moreira OC. Detection and genotyping of trypanosoma cruzi from acai products commercialized in rio de janeiro and para, brazil. Parasit Vectors 2018; 11: 233.

402 Figueiredo M F. B., Schubach TM. Efficacy of an indirect immunofluorescence test in the diagnosis of canine leishmaniosis. Vet J 2010; 186: 123-4.

403 Figueiredo LD de V F. B.Nascimento. Serological diagnosis of feline tegumentary leishmaniasis by indirect immunofluorescence (IFI) and enzyme-linked immunosorbent assay (ELISA) in an endemic area in brazil. Acta Scientiae Veterinariae 2016; 44. <Go to ISI>://WOS:000392090700001.

404 Fikru A R., Buscher P. Trypanosome infection in dromedary camels in eastern ethiopia: Prevalence, relative performance of diagnostic tools and host related risk factors. Vet Parasitol 2015; 211: 175-81.

405 Silva Filho T Mauro de F., Navarro IT. Infection by toxoplasma gondii and leishmania spp. In humans and dogs from rural settlements in northern paraná state, brazil. Semina: Ciências Agrárias 2012; 33: 3251-64.

406 Freitas S Y. B. N., Amora SSA. Natural infection by trypanosoma cruzi in triatomines and seropositivity for chagas disease of dogs in rural areas of rio grande do norte, brazil. Rev Soc Bras Med Trop 2018; 51: 190-7. 
407 Galaviz-Silva M-H L., Molina-Garza ZJ. Prevalence of trypanosoma cruzi infection in dogs and small mammals in nuevo leon, mexico. Rev Argent Microbiol 2017; 49: 216-23.

408 Garcia M N., Dominguez M. Evidence of leishmania infantum infection in rabbits (oryctolagus cuniculus) in a natural area in madrid, spain. Biomed Res Int 2014; 2014: 318254.

409 Gari A F. R., Claes F. Comparative diagnosis of parasitological, serological, and molecular tests in dourine-suspected horses. Trop Anim Health Prod 2010; 42: 1649-54.

410 Garvin M M. C., Crain SK. Prevalence of hematozoa in overwintering american redstarts (setophaga ruticilla): No evidence for local transmission. J Wildl Dis 2004; 40: 115-8.

411 Gavgani M A. S., Davies CR. Domestic dog ownership in iran is a risk factor for human infection with leishmania infantum. Am J Trop Med Hyg 2002; 67: 511-5.

412 Ghaemi Z M., Jannati Pirouz H. Evaluation of trypanosama evansi prevalence and risk factors in the one-humped camels (camelus dromedarius) of the north-east of iran by a real-time PCR test. Prev Vet Med 2019; 168: 60-5.

413 Giannakopoulos CNP A.Tsokana. Molecular investigation and geographical distribution of leishmania spp infection in stray and owned cats (felis catus) in thessaly, central greece. Journal of the Hellenic Veterinary Medical Society 2017; 68: 27-34.

414 Gicheru J M. M., Suleman MA. Prevalence of antibodies and cell mediated immune response against leishmania major in feral nonhuman primates from kenya. Acta Trop 2009; 109: 136-40.

415 Gontijo da S C. M., Melo MN. Epidemiological studies of an outbreak of cutaneous leishmaniasis in the rio jequitinhonha valley, minas gerais, brazil. Acta Trop 2002; 81: 14350 .

416 Grisard C-P E. C., Steindel M. Trypanosoma cruzi infection in didelphis marsupialis in santa catarina and arvoredo islands, southern brazil. Mem Inst Oswaldo Cruz 2000; 95 : 795-800.

417 Guimaraes B K. S., Abreu-Silva AL. Canine visceral leishmaniasis in sao jose de ribamar, maranhao state, brazil. Vet Parasitol 2005; 131: 305-9.

418 Gunasekara S E., Yokoyama N. Epidemiological survey of hemoprotozoan parasites in cattle from low-country wet zone in sri lanka. Parasitol Int 2019; 71: 5-10.

419 Haas L M., Hrehova Z. Occurrence of blood parasites and intensity of infection in prunella modularis in the montane and subalpine zone in the slovak carpathians. Acta Parasitol 2012; 57: 221-7. 
420 Haenen L O. L. M., Breteler JK. The health status of european silver eels, anguilla anguilla, in the dutch river rhine watershed and lake IJsselmeer. Aquaculture 2010; 309: $15-24$.

421 Haji M I. J., Namangala B. Occurrence of haemoparasites in cattle in monduli district, northern tanzania. Onderstepoort J Vet Res 2014; 81. DOI:10.4102/ojvr.v81i1.843.

422 Hamad F I., Bittar F. Wild gorillas as a potential reservoir of leishmania major.J Infect Dis 2015; 211: 267-73.

423 Hamarsheh N O., Al-Jawabreh A. Serological and molecular survey of leishmania parasites in apparently healthy dogs in the west bank, palestine. Parasit Vectors 2012; 5: 183.

424 Hamill K L. C., Picozzi K. Domestic pigs as potential reservoirs of human and animal trypanosomiasis in northern tanzania. Parasit Vectors 2013; 6: 322.

425 Hanel D J., Votypka J. Blood parasites in northern goshawk (accipiter gentilis) with an emphasis to leucocytozoon toddi. Parasitol Res 2016; 115: 263-70.

426 Hassan 0 M. M., Elnaiem DE. Role of the domestic dog as a reservoir host of leishmania donovani in eastern sudan. Parasit Vectors 2009; 2: 26.

427 Hernandez S C., Ramirez JD. Untangling the transmission dynamics of primary and secondary vectors of trypanosoma cruzi in colombia: Parasite infection, feeding sources and discrete typing units. Parasit Vectors 2016; 9: 620.

428 Herrera L C. P., Wesson DM. Genotype diversity of trypanosoma cruzi in small rodents and triatoma sanguisuga from a rural area in new orleans, louisiana. Parasit Vectors 2015; 8: 123.

429 Hodo R C. L., Hamer SA. Repeated cross-sectional study of trypanosoma cruzi in shelter dogs in texas, in the context of dirofilaria immitis and tick-borne pathogen prevalence. J Vet Intern Med 2019; 33: 158-66.

430 Hofmann H M., Joachim A. Vector-borne pathogens affecting shelter dogs in eastern crete, greece. Parasitol Res 2019; 118: 1661-6.

431 Holland T W. G., Vercruysse J. Prevalence of trypanosoma evansi in water buffaloes in remote areas in northern vietnam using PCR and serological methods. Trop Anim Health Prod 2004; 36: 45-8.

432 Holmstad A P. R., Skorping A. Standard sampling techniques underestimate prevalence of avian hematozoa in willow ptarmigan (lagopus lagopus). J Wildl Dis 2003; 39: 354-8.

433 Hussain ZG M.Saeed. Molecular detection and seasonal prevalence of trypanosoma brucei and its effect on hematobiochemical parameters in donkeys from dera ghazi khan district in southern punjab, pakistan. Pakistan Journal of Zoology 2016; 48: 1781-6. 
434 Hussain K R., Mehmood K. Clinico-hematological and oxidative stress status in nili ravi buffaloes infected with trypanosoma evansi. Microb Pathog 2018; 123: 126-31.

435 Jafari N R., Parvizi P. Molecular characterization of sandflies and leishmania detection in main vector of zoonotic cutaneous leishmaniasis in abarkouh district of yazd province, iran. Asian Pac J Trop Med 2013; 6: 792-7.

436 Jakes O K. A., Adlard R. Hemoprotozoa of freshwater turtles in queensland. J Wildl Dis 2001; 37: 12-9.

437 Jing M Z., Inoue N. A field study to estimate the prevalence of bovine african trypanosomosis in butaleja district, uganda. J Vet Med Sci 2009; 71: 525-7.

438 Karakus A M., Ozbel Y. Vector and reservoir surveillance study in a canine and human leishmaniasis endemic area in most western part of turkey, karaburun. Acta Trop 2019; 190: 177-82.

439 Karbowiak R Grzegorz, Wita I. Natural infections of small mammals with blood parasites on the borderland of boreal and temperate forest zones. Acta Theriologica 2005; 50: 31-42.

440 Karimuribo M E. D., Ballingall KT. Analysis of host genetic factors influencing african trypanosome species infection in a cohort of tanzanian bos indicus cattle. Vet Parasitol 2011; 179: 35-42.

441 Kassa TC T.Eguale. Prevalence of camel trypanosomosis and its vectors in fentale district, south east shoa zone, ethiopia. Veterinarski Arhiv 2011; 81: 611-21.

442 Kato U H., Hashiguchi Y. Establishment of a mass screening method of sand fly vectors for leishmania infection by molecular biological methods. Am J Trop Med Hyg 2007; 77: 324-9.

443 Keck J N.Dereuer. Epidemiology of canine leishmaniasis by cross-sectional study in the french focus of cevennes. Revue De Medecine Veterinaire 2003; 154: 599-604.

444 Kelly B E., Lymbery AJ. Haematozoa of wild catfishes in northern australia. Int J Parasitol Parasites Wildl 2018; 7: 12-7.

445 Kenubih D A., Lemma W. Preliminary survey of domestic animal visceral leishmaniasis and risk factors in north-west ethiopia. Trop Med Int Health 2015; 20: 20510.

446 Khanmohammadi ER M.Fallah. Study on seroprevalence of canine visceral leishmaniasis (CVL) in ownership dogs of sarab, east azerbaijan, province, northwest of iran with indirect immuno fluorescence antibody test (IFAT) and its health importance in 2008-2009. Journal of Animal and Veterinary Advances 2010; 9: 139-43. 
447 Kilic CO S.Babur. Investigation of anti-toxoplasma gondii and anti-leishmania infantum antibodies among sivas kangal dogs. Turkish Journal of Veterinary \& Animal Sciences 2008; 32: 299-304.

448 Kovalenko R D. A., Baneth G. Canine leishmaniosis and its relationship to human visceral leishmaniasis in eastern uzbekistan. Parasit Vectors 2011; 4: 58.

449 Kubacka G J., Podmokla E. Correlates of blood parasitism in a threatened marshland passerine: Infection by kinetoplastids of the genus trypanosoma is related to landscape metrics of habitat edge. Parasitology 2019; 146: 1036-46.

450 Laohasinnarong T D., Inoue N. Prevalence of trypanosoma sp. In cattle from tanzania estimated by conventional PCR and loop-mediated isothermal amplification (LAMP).

Parasitol Res 2011; 109: 1735-9.

451 Laranjeira M D. F., Laurenti MD. Serological and infection statuses of dogs from a visceral leishmaniasis-endemic area. Rev Saude Publica 2014; 48: 563-71.

452 Leca Junior G N. F., Silva FL. Epidemiology of canine leishmaniasis in southern bahia, brazil. Acta Trop 2015; 148: 115-9.

453 Lemma B W., Hailu A. Preliminary study on investigation of zoonotic visceral leishmaniasis in endemic foci of ethiopia by detecting leishmania infections in rodents. Asian Pac J Trop Med 2017; 10: 418-22.

454 Leontides S L. S., Mylonakis ME. A cross-sectional study of leishmania spp. Infection in clinically healthy dogs with polymerase chain reaction and serology in greece. Vet Parasitol 2002; 109: 19-27.

455 Leppert D L. L., Kaltenecker GS. Survey of blood parasites in two forest owls, northern saw-whet owls and flammulated owls, of western north america.J Wildl Dis 2008; 44: 475-9.

456 Lima D-T B. S., Brandao-Filho SP. Small mammals as hosts of leishmania spp. In a highly endemic area for zoonotic leishmaniasis in north-eastern brazil. Trans $R$ Soc Trop Med Hyg 2013; 107: 592-7.

457 Lima-Oliveira F T. M., Almeida CE. Molecular eco-epidemiology on the sympatric chagas disease vectors triatoma brasiliensis and triatoma petrocchiae: Ecotopes, genetic variation, natural infection prevalence by trypanosomatids and parasite genotyping. Acta Trop 2020; 201: 105188.

458 Lins S T. N. B., Ramos RAN. Seroprevalence and spatial distribution of canine leishmaniasis in an endemic region in brazil: How has the situation changed after 10 years? Rev Soc Bras Med Trop 2018; 51: 680-2.

459 Lisi D 0., Maroli M. Persistence of phlebotomine leishmania vectors in urban sites of catania (sicily, italy). Parasit Vectors 2014; 7: 560. 
460 Lisulo S M., Namangala B. Determination of the prevalence of african trypanosome species in indigenous dogs of mambwe district, eastern zambia, by loop-mediated isothermal amplification. Parasit Vectors 2014; 7: 19.

461 Lopes S A. P., Cordeiro-da-Silva A. Prevalence of antibodies to leishmania infantum and toxoplasma gondii in horses from the north of portugal. Parasit Vectors 2013; 6: 178.

462 Lopes SE P. M., Sousa VR. Seroprevalence and risk factors associated with visceral leishmaniasis in dogs in jaciara, state of mato grosso. Rev Soc Bras Med Trop 2014; 47: 7915 .

463 Maganga M G. D., Ollomo B. Molecular identification of trypanosome species in trypanotolerant cattle from the south of gabon. Parasite 2017; $24: 4$.

464 Maharjan DR M.Mishra. Impact of emerging zoonotic diseases on animal health. 2006; 1081: 320-1.

465 Maia A C., Roura X. Molecular detection of leishmania infantum, filariae and wolbachia spp. In dogs from southern portugal. Parasit Vectors 2016; 9: 170.

466 Maia C C., Campino L. Serological investigation of leishmania infantum, dirofilaria immitis and angiostrongylus vasorum in dogs from southern portugal. Parasit Vectors 2015; 8: 152.

467 Maia G C., Campino L. Feline leishmania infection in a canine leishmaniasis endemic region, portugal. Vet Parasitol 2010; 174: 336-40.

468 Maia R C., Campino L. Prevalence of dirofilaria immitis antigen and antibodies to leishmania infantum in cats from southern portugal. Parasitol Int 2015; 64: 154-6.

469 Malele M II, Kimbita EN. Multiple trypanosoma infections are common amongst glossina species in the new farming areas of rufiji district, tanzania. Parasit Vectors 2011; 4: 217.

470 Foglia Manzillo G V., Oliva G. Serological and entomological survey of canine leishmaniasis in lampedusa island, italy. BMC Vet Res 2018; 14: 286.

471 Marcelino F A. P., Gontijo CM. Molecular detection of leishmania braziliensis in rattus norvegicus in an area endemic for cutaneous leishmaniasis in brazil. Vet Parasitol 2011; 183: 54-8.

472 Martinez-Sanchez C A., Alejandre-Aguilar R. Effect of ectoparasitic pimeliaphilus plumifer mites (acari: Pterygosomatidae) on meccus pallidipennis (hemiptera: Reduviidae) and several other chagas' disease vectors under laboratory conditions. Exp Appl Acarol 2007; 42: 139-49.

473 Matete GO. Occurrence, clinical manifestation and the epidemiological implications of naturally occurring canine trypanosomosis in western kenya. Onderstepoort J Vet Res 2003; 70: 317-23. 
474 Mattioli F R. C., Jaitner J. Estimation of trypanosomal status by the buffy coat technique and an antibody ELISA for assessment of the impact of trypanosomosis on health and productivity of n'dama cattle in the gambia. Vet Parasitol 2001; 95: 25-35.

475 Maziero T-S N., Nascimento AJ. Rural-urban focus of canine visceral leishmaniosis in the far western region of santa catarina state, brazil. Vet Parasitol 2014; 205: 92-5.

476 Medkour D H., Mediannikov O. Potential animal reservoirs (dogs and bats) of human visceral leishmaniasis due to leishmania infantum in french guiana. PLoS Negl Trop Dis 2019; 13: e0007456.

477 Mekuria AR S.Eyob. A cross-sectional study of equine trypanosomosis and its vectors in wolayta zone, southern ethiopia. Journal of Animal and Veterinary Advances 2010; 9: 2061-6.

478 Melo T-N S. N., Belo VS. Prevalence of visceral leishmaniasis in a population of freeroaming dogs as determined by multiple sampling efforts: A longitudinal study analyzing the effectiveness of euthanasia. Prev Vet Med 2018; 161: 19-24.

479 Millan J. Molecular investigation of vector-borne parasites in wild micromammals, barcelona (spain). Parasitol Res 2018; 117: 3015-8.

480 Miranda R J. C., Barral A. Frequency of infection of lutzomyia phlebotomines with leishmania braziliensis in a brazilian endemic area as assessed by pinpoint capture and polymerase chain reaction. Mem Inst Oswaldo Cruz 2002; 97: 185-8.

481 Miro H G., Pedraza-Diaz S. First description of naturally acquired tritrichomonas foetus infection in a persian cattery in spain. Parasitol Res 2011; 109: 1151-4.

482 Mirzaei R A., Parvizi P. Isolation and detection of leishmania species among naturally infected rhombomis opimus, a reservoir host of zoonotic cutaneous leishmaniasis in turkemen sahara, north east of iran. Exp Parasitol 2011; 129: 375-80.

483 Mohammad B K. N., Zainal-Abidin AH. Protozoan parasites of four species of wild anurans from a local zoo in malaysia. Trop Biomed 2013; 30: 615-20.

484 Montenegro J V. M., Zeledon R. Chagas disease in dogs from endemic areas of costa rica. Mem Inst Oswaldo Cruz 2002; 97: 491-4.

485 Montoya G A., Miro G. Implications of zoonotic and vector-borne parasites to freeroaming cats in central spain. Vet Parasitol 2018; 251: 125-30.

486 Morales M E. A., Lescano AG. Prevalence of trypanosoma cruzi and other trypanosomatids in frequently-hunted wild mammals from the peruvian amazon. Am J Trop Med Hyg 2017; 97: 1482-5.

487 Morelli C S., Traversa D. Exposure of client-owned cats to zoonotic vector-borne pathogens: Clinic-pathological alterations and infection risk analysis. Comp Immunol Microbiol Infect Dis 2019; 66: 101344. 
488 Morganti V G., Gramiccia M. Emerging feline vector-borne pathogens in italy. Parasit Vectors 2019; 12: 193.

489 Moudy M R. M., Wesson DM. Factors associated with peridomestic triatoma sanguisuga (hemiptera: Reduviidae) presence in southeastern louisiana. J Med Entomol 2014; 51: 1043-50.

490 Moya G S. L., Liotta DJ. Leishmania infantum DNA detected in phlebotomine species from puerto iguazu city, misiones province, argentina. Acta Trop 2017; 172: 122-4.

491 Murphy M N., Miles MA. Lineage-specific rapid diagnostic tests can resolve trypanosoma cruzi TcII/v/VI ecological and epidemiological associations in the argentine chaco. Parasit Vectors 2019; 12: 424.

492 Nadeem AC A.Aslam. Indirect fluorescent antibody technique based prevalence of surra in equines. Pakistan Veterinary Journal 2011; 31: 169-70.

493 Nair R A. S., Ghosh S. Haemoprotozoa of cattle in northern kerala, india. Trop Biomed 2011; 28: 68-75.

494 Nardoni A S., Mancianti F. Serological and molecular findings of leishmania infection in healthy donkeys (equus asinus) from a canine leishmaniosis endemic focus in tuscany, italy: A preliminary report. Pathogens 2019; 8. DOI:10.3390/pathogens8030099.

495 Navea-Perez D-S H. M., Martin-Sanchez J. Leishmania infantum in wild rodents: Reservoirs or just irrelevant incidental hosts? Parasitol Res 2015; 114: 2363-70.

496 Ngomtcho W S. C. H., Achukwi MD. Molecular screening of tsetse flies and cattle reveal different trypanosoma species including t. Grayi and t. Theileri in northern cameroon. Parasit Vectors 2017; 10: 631.

497 Nguyen M T. T., Inoue N. Application of crude and recombinant ELISAs and immunochromatographic test for serodiagnosis of animal trypanosomosis in the umkhanyakude district of KwaZulu-natal province, south africa. J Vet Med Sci 2015; 77: 217-20.

498 Nunes L J. B., Marques MJ. Leishmania infantum INFECTION IN DOGS FROM THE SOUTHERN REGION OF MINAS GERAIS STATE, BRAZIL. Rev Inst Med Trop Sao Paulo 2016; 58: 75 .

499 Nurcahyo Y W., Prastowo J. The prevalence of horse trypanosomiasis in sumba island, indonesia and its detection using card agglutination tests. Vet World 2019; 12: 64652.

500 Odeniran M P. O., Welburn SC. Molecular identification of bloodmeal sources and trypanosomes in glossina spp., Tabanus spp. And stomoxys spp. Trapped on cattle farm settlements in southwest nigeria. Med Vet Entomol 2019; 33: 269-81. 
501 Odongo D S., Magez S. Comparative evaluation of the nested ITS PCR against the 18S PCR-RFLP in a survey of bovine trypanosomiasis in kwale county, kenya. J Vet Diagn Invest 2016; 28: 589-94.

502 Oleaga Z A., Ferroglio E. Leishmania in wolves in northern spain: A spreading zoonosis evidenced by wildlife sanitary surveillance. Vet Parasitol 2018; 255: 26-31.

503 Oliveira P F. S., Pacheco RS. PCR-based diagnosis for detection of leishmania in skin and blood of rodents from an endemic area of cutaneous and visceral leishmaniasis in brazil. Vet Parasitol 2005; 129: 219-27.

504 Oliveira G T. N., Silva FL. Diagnosis and epidemiology of canine leishmaniasis in southeastern bahia, brazil. Genet Mol Res 2016; 15. DOI:10.4238/gmr.15038684.

505 Orozco E M. M., Gurtler RE. A comparative study of trypanosoma cruzi infection in sylvatic mammals from a protected and a disturbed area in the argentine chaco. Acta Trop 2016; 155: 34-42.

506 Padilla M A. M., Basombrio MA. Canine infection and the possible role of dogs in the transmission of american tegumentary leishmaniosis in salta, argentina. Vet Parasitol 2002; 110: $1-0$.

507 Palangar HK M.Jamali. Molecular study of cutaneous leishmaniasis human reservoirs and infections in bastak. Iioab Journal 2017; 8: 33-8.

508 Panti-May R J. A., Costa F. A survey of zoonotic pathogens carried by house mouse and black rat populations in yucatan, mexico. Epidemiol Infect 2017; 145: 2287-95.

509 Paoletta LA M. S., Wilkowsky SE. Epidemiology of babesia, anaplasma and trypanosoma species using a new expanded reverse line blot hybridization assay. Ticks Tick Borne Dis 2018; 9: 155-63.

510 Parrado R R., Garcia AL. Prevalence of leishmania spp. Infection in domestic dogs in chapare, bolivia. Vet Parasitol 2011; 177: 171-4.

511 Parvizi A P., Baghban N. Occurrence of low density of leishmania infantum in sandflies from a new focus of visceral leishmaniasis in northwest of iran. J Vector Borne Dis 2013; 50: 127-32.

512 Pasa TV S., Ozbel Y. Detection of leishmania major and leishmania tropica in domestic cats in the ege region of turkey. Vet Parasitol 2015; 212: 389-92.

513 Pasos-Pinto LS-M S.Sanchez-Garcia. Genetic diversity and prevalence of leishmania mexicana in bichromomyia olmeca olmeca(1) in an endemic area of mexico. Southwestern Entomologist 2017; 42: 983-94.

514 Perez F T. D., Coura JR. Prevalence of american trypanosomiasis and leishmaniases in domestic dogs in a rural area of the municipality of sao joao do piaui, piaui state, brazil. Rev Inst Med Trop Sao Paulo 2016; 58: 79. 
515 Piantedosi V D., Gramiccia M. Epidemiological survey on leishmania infection in red foxes (vulpes vulpes) and hunting dogs sharing the same rural area in southern italy. Acta Parasitol 2016; 61: 769-75.

516 Pineda S V., Calzada JE. Prevalence of trypanosome infections in dogs from chagas disease endemic regions in panama, central america. Vet Parasitol 2011; 178: 360-3.

517 Pinto O-M C. M., Grijalva MJ. Infection by trypanosomes in marsupials and rodents associated with human dwellings in ecuador. J Parasitol 2006; 92: 1251-5.

518 Pinto O-M C. M., Perkins SL. Bats, trypanosomes, and triatomines in ecuador: New insights into the diversity, transmission, and origins of trypanosoma cruzi and chagas disease. PLoS One 2015; 10: e0139999.

519 Qiu K Y., Sugimoto C. Molecular characterization and phylogenetic analysis of trypanosoma spp. Detected from striped leaf-nosed bats (hipposideros vittatus) in zambia. Int J Parasitol Parasites Wildl 2019; 9: 234-8.

520 Quintal RE A. P., Nunes CM. Leishmania spp. In didelphis albiventris and micoureus paraguayanus (didelphimorphia: Didelphidae) of brazil. Vet Parasitol 2011; 176: 112-9.

521 Ramsey G-C J. M., Ibarra-Cerdena CN. Ecological connectivity of trypanosoma cruzi reservoirs and triatoma pallidipennis hosts in an anthropogenic landscape with endemic chagas disease. PLoS One 2012; 7: e46013.

522 Rassi KM Y.Azizi. The seminested PCR based detection of leishmania infantum infection in asymptomatic dogs in a new endemic focus of visceral leishmaniasis in iran. Iranian Journal of Arthropod-Borne Diseases 2007; 1: 38-42.

523 Razzaghi Maensh SG M.Mahabadi. Prevalence of canine visceral leishmaniasis in dogs at adrestan district detected by PCR. Veterinary Research 2012; 5: 22-5.

524 Rodrigues P F. T., Lopes AP. Seroprevalence of toxoplasma gondii and leishmania spp. In domestic donkeys from portugal. Rev Bras Parasitol Vet 2019; 28: 172-6.

525 Rodriguez T-J N. F., Gutierrez C. The role of wild rodents in the transmission of trypanosoma evansi infection in an endemic area of the canary islands (spain). Vet Parasitol 2010; 174: 323-7.

526 Rodriguez OA, Matta NE. Blood parasites in some birds from eastern plains of colombia. Mem Inst Oswaldo Cruz 2001; 96: 1173-6.

527 Rossi B E., Maroli M. Seasonal phenology, host-blood feeding preferences and natural leishmania infection of phlebotomus perniciosus (diptera, psychodidae) in a highendemic focus of canine leishmaniasis in rome province, italy. Acta Trop 2008; 105: 15865. 
528 Rosypal C-V A. C., Lindsay DS. Serological survey of leishmania infantum and trypanosoma cruzi in dogs from urban areas of brazil and colombia. Vet Parasitol 2007; 149: $172-7$.

529 Ruiz N J. P., Malele I. The role of domestic animals in the epidemiology of human african trypanosomiasis in ngorongoro conservation area, tanzania. Parasit Vectors 2015; 8: 510 .

530 Ruiz-Pina HA, Cruz-Reyes A. The opossum didelphis virginiana as a synanthropic reservoir of trypanosoma cruzi in dzidzilche, yucatan, mexico. Mem Inst Oswaldo Cruz 2002; 97: 613-20.

531 Saldana C A., Chaves LF. Risk factors associated with trypanosoma cruzi exposure in domestic dogs from a rural community in panama. Mem Inst Oswaldo Cruz 2015; 110: 93644.

532 Saldana S A., Calzada JE. A darker chromatic variation of rhodnius pallescens infected by specific genetic groups of trypanosoma rangeli and trypanosoma cruzi from panama. Parasit Vectors 2018; 11: 423.

533 Sallemi R S., Gharbi M. Molecular prevalence and phylogenetic analysis of theileria annulata and trypanosoma evansi in cattle in northern tunisia. Vet Med Sci 2018; 4: 17-25.

534 Salvatore A D., Galuppi R. Molecular evidence of leishmania infantum in ixodes ricinus ticks from dogs and cats, in italy. Vet Ital 2014; 50: 307-12.

535 Salzer P J. S., Gillespie TR. Impact of anthropogenic disturbance on native and invasive trypanosomes of rodents in forested uganda. Ecohealth 2016; 13: 698-707.

536 Santaella 0 J., Quinnell RJ. Leishmania (viannia) infection in the domestic dog in chaparral, colombia. Am J Trop Med Hyg 2011; 84: 674-80.

537 Sarquis C-C O., Lima MM. Eco-epidemiology of chagas disease in northeastern brazil: Triatoma brasiliensis, t. Pseudomaculata and rhodnius nasutus in the sylvatic, peridomestic and domestic environments. Parasitol Res 2012; 110: 1481-5.

538 Sastre F N., Altet L. Detection of leishmania infantum in captive wolves from southwestern europe. Vet Parasitol 2008; 158: 117-20.

539 Sazmand E A., Joachim A. Molecular identification of hemoprotozoan parasites in camels (camelus dromedarius) of iran. Iran J Parasitol 2016; 11: 568-73.

540 Selmi MBS R.Dhibi. Evidence of natural infections with trypanosoma, anaplasma and babesia spp. In military livestock from tunisia. Tropical Biomedicine 2019; 36: 742-57.

541 Shadomy W S. V., Chappell CL. Combined use of enzyme-linked immunosorbent assay and flow cytometry to detect antibodies to trypanosoma cruzi in domestic canines in texas. Clin Diagn Lab Immunol 2004; 11: 313-9. 
542 Sharbatkhori S M., Parvizi P. Molecular variation in leishmania parasites from sandflies species of a zoonotic cutaneous leishmaniasis in northeast of iran. J Vector Borne Dis 2014; 51: 16-21.

543 Sharma BK A.Sharma. Incidence of haemoprotozoan infection in canines in and around mathura. Veterinary Practitioner 2011; 12: 149-50.

544 Silbermayr L K., Solkner J. A novel qPCR assay for the detection of african animal trypanosomosis in trypanotolerant and trypanosusceptible cattle breeds. PLoS Negl Trop Dis 2013; 7: e2345.

545 Silva Rde R C., Alves LC. Detection of antibodies against leishmania infantum in cats (felis catus) from the state of pernambuco, brazil. Rev Soc Bras Med Trop 2014; 47: 108-9.

546 Simo S G., Asonganyi T. Identification of different trypanosome species in the midguts of tsetse flies of the malanga (kimpese) sleeping sickness focus of the democratic republic of congo. Parasit Vectors 2012; 5: 201.

547 Singh P N., Kumar R. A comparative evaluation of parasitological, serological and DNA amplification methods for diagnosis of natural trypanosoma evansi infection in camels. Vet Parasitol 2004; 126: 365-73.

548 Singla D L. D., Ba MS. Conventional and molecular diagnosis of haemo-protozoan infectionsin cattle and equids from republic of guinea and india. Indian Journal of Animal Research 2017; 52. DOI:10.18805/ijar.v0iOF.6988.

549 Sobrino F R., Gortazar C. Characterization of widespread canine leishmaniasis among wild carnivores from spain. Vet Parasitol 2008; 155: 198-203.

550 Solano-Gallego L L., Breitschwerdt E. A serological study of exposure to arthropodborne pathogens in dogs from northeastern spain. Vet Res 2006; 37: 231-44.

551 Solano-Gallego M L., Ferrer L. Prevalence of leishmania infantum infection in dogs living in an area of canine leishmaniasis endemicity using PCR on several tissues and serology. J Clin Microbiol 2001; 39: 560-3.

552 Solano-Gallego R L., Trotta M. Detection of leishmania infantum DNA mainly in rhipicephalus sanguineus male ticks removed from dogs living in endemic areas of canine leishmaniosis. Parasit Vectors 2012; 5: 98.

553 Spada C E., Proverbio D. Prevalence of leishmania infantum and co-infections in stray cats in northern italy. Comp Immunol Microbiol Infect Dis 2016; 45: 53-8.

554 Sumbria S D., Bal MS. Equine trypanosomosis in central and western punjab: Prevalence, haemato-biochemical response and associated risk factors. Acta Trop 2014;

138: $44-50$. 
555 Sumbria S D., Kaur P. Comparative seroprevalence and risk factor analysis of trypanosoma evansi infection in equines from different agro-climatic zones of punjab (india). Rev Sci Tech 2017; 36: 971-9.

556 Sun G K., Chen JP. Prevalence of canine leishmaniasis in beichuan county, sichuan, china and phylogenetic evidence for an undescribed leishmania sp. In china based on 7SL RNA. Parasit Vectors 2012; 5: 75.

557 Szpeiter F B. B., Marcili A. Bat trypanosomes from tapajos-arapiuns extractive reserve in brazilian amazon. Rev Bras Parasitol Vet 2017; 26: 152-8.

558 Tabar A M. D., Roura X. Vector-borne infections in cats: Molecular study in barcelona area (spain). Vet Parasitol 2008; 151: 332-6.

559 Tadesse A, Tsegaye B. Bovine trypanosomosis and its vectors in two districts of bench maji zone, south western ethiopia. Trop Anim Health Prod 2010; 42: 1757-62.

560 Tafese M W., Fentahun T. Prevalence of bovine trypanosomosis and its vectors in two districts of east wollega zone, ethiopia. Onderstepoort J Vet Res 2012; 79: E1-4.

561 Kante Tagueu F S., Simo G. Prevalence of sodalis glossinidius and different trypanosome species in glossina palpalis palpalis caught in the fontem sleeping sickness focus of the southern cameroon. Parasite 2018; 25: 44.

562 Tamay-Segovia B-D Paulino, Retana-Guiascón OG. Presence of virginia opossum (didelphis virginiana) and pic (triatoma dimidiata) infected with trypanosoma cruzi in urban areas: Preliminary evaluation in the city of campeche, mexico. Austral journal of veterinary sciences 2017; 49: 35-8.

563 Tanczos B B., Farkas R. First record of autochthonous canine leishmaniasis in hungary. Vector Borne Zoonotic Dis 2012; 12: 588-94.

564 Tehseen J Sonia, Qamar MF. Field investigation of trypanosoma evansi and comparative analysisof diagnostic tests in horses from bahawalpur, pakistan. Turkish Journal of Veterinary and Animal Sciences 2017; 41: 288-93.

565 Tomas-Perez K M., Fisa R. First report of natural infection in hedgehogs with leishmania major, a possible reservoir of zoonotic cutaneous leishmaniasis in algeria. Acta Trop 2014; 135: 44-9.

566 Tonelli T G. B., Andrade Filho JD. Leishmania (viannia) braziliensis infection in wild small mammals in ecotourism area of brazil. PLoS One 2017; 12: e0190315.

567 Tono F Rafi Rabecca, Ibitoye EB. Presence of trypanosome species and anemic status of dogs in zuru, nigeria. Macedonian Veterinary Review 2015; 38: 217-22.

568 Toz E S. O., Ozbel Y. [An epidemiological study on canine leishmaniasis (CanL) and sand flies in northern cyprus]. Turkiye Parazitol Derg 2013; 37: 107-12. 
569 Toz NE S. O.Sakru. Serological and entomological survey of zoonotic visceral leishmaniasis in denizli province, aegean region, turkey. New Microbiologica 2009; 32: 93100.

570 Trindade NA de A C. N. D.da Cunha. Cunha. Immunofluorescent antibody test (IFAT) for trypanosoma cruzi in dogs from urban and rural areas of pelotas, RS. Boletim De Industria Animal 2015; 72: 111-6.

571 Tsakmakidis A Iota, Diakou A. Leishmania infection in rodents in greece. Trop Med Int Health 2017; 22: 1523-32.

572 Valadas M S., Gennari SM. Occurrence of antibodies anti-neospora caninum, antitoxoplasma gondii, and anti-leishmania chagasi in serum of dogs from para state, amazon, brazil. Parasitol Res 2010; 107: 453-7.

573 Valkiūnas I G., Shapoval AP. High prevalence of blood parasites in hawfinch coccothraustes coccothraustes. Journal of Natural History 2003; 37: 2647-52.

574 Valkiunas I G., Causey D. Additional observations on blood parasites of birds in costa rica. J Wildl Dis 2004; 40: 555-61.

575 Valkiunas S G., Smith TB. Further observations on the blood parasites of birds in uganda. J Wildl Dis 2005; 41: 580-7.

576 Villagran JA de D M. E.Martinez-Ibarra. Pathological alterations and prevalence of trypanosoma cruzi in opossums from western mexico. Boletin De Malariologia Y Salud Ambiental 2011; 51: 87-8.

577 Villena G-P F. E., Ampuero JS. First report of trypanosoma cruzi infection in salivary gland of bats from the peruvian amazon. Am J Trop Med Hyg 2018; 99: 723-8.

578 Dohlen C von A. R., Sharma RN. Prevalence of antibodies against visceralizing leishmania spp. In brown rats from grenada, west indies. Vet World 2018; 11: 1321-5.

579 Votypka P J., Petrzelkova KJ. An unexpected diversity of trypanosomatids in fecal samples of great apes. Int J Parasitol Parasites Wildl 2018; 7: 322-5.

580 Voyvoda ST H.Pasa. Prevalence of leishmania infantum and dirofilaria immitis infection in dogs in aydin province and the town of selcuk, izmir, turkey. Turkish Journal of Veterinary \& Animal Sciences 2004; 28: 1105-11.

581 Wang H J. Y., Chen HT. The prevalence of canine leishmania infantum infection in western china detected by PCR and serological tests. Parasit Vectors 2011; 4: 69.

582 Wong SM Y. Y., Dumonteil E. Molecular epidemiology of trypanosoma cruzi and triatoma dimidiata in costal ecuador. Infect Genet Evol 2016; 41: 207-12.

583 Yabsley MJ, Noblet GP. Seroprevalence of trypanosoma cruzi in raccoons from south carolina and georgia. J Wildl Dis 2002; 38: 75-83. 
584 Yefi-Quinteros M-SM E., Cattan PE. Trypanosoma cruzi load in synanthropic rodents from rural areas in chile. Parasit Vectors 2018; 11: 171.

585 Zanet S S., Ferroglio E. Epidemiology of leishmania infantum, toxoplasma gondii, and neospora caninum in rattus rattus in absence of domestic reservoir and definitive hosts. Vet Parasitol 2014; 199: 247-9.

586 Zangooie MK F.Ganjali. Molecular detection of trypanosoma evansi based on ITS1 rDNA gene in camelus dromedarius in sistan region, iran. Tropical Biomedicine 2018; 35: $1140-7$.

587 Zhang G J. R., Chen JP. Molecular detection, identification and phylogenetic inference of leishmania spp. In some desert lizards from northwest china by using internal transcribed spacer 1 (ITS1) sequences. Acta Trop 2016; 162: 83-94.

588 Zhao Y G. H., Wang HF. Epidemiological investigation of asymptomatic dogs with leishmania infection in southwestern china where visceral leishmaniasis is intractable. Korean J Parasitol 2016; 54: 797-801.

589 Zivicnjak M T., Baric-Rafaj R. A seroepidemiologic survey of canine visceral leishmaniosis among apparently healthy dogs in croatia. Vet Parasitol 2005; 131: 35-43.

590 Zivicnjak FK T.Martinkovic. Serological and entomological studies of canine leishmaniosis in croatia. Veterinarski Arhiv 2011; 81: 99-110.

591 Zoghlami C Z., Zhioua E. Interaction between canine and human visceral leishmaniases in a holoendemic focus of central tunisia. Acta Trop 2014; 139: 32-8.

592 Ollerton J, Winfree R, Tarrant S. How many flowering plants are pollinated by animals? Oikos 2011; 120: 321-6.

593 Gallai N, Salles J-M, Settele J, Vaissière BE. Economic valuation of the vulnerability of world agriculture confronted with pollinator decline. Ecological Economics 2009; 68: 81021.

594 Morse R, Calderone N. The value of honey bees as pollinators of u.s. Crops in 2000. Bee Cult 2000; 128: 1-5.

595 Cameron SA, Sadd BM. Global trends in bumble bee health. Annual Review of Entomology 2020; 65: 209-32.

596 Mallinger HRAG Rachel E. AND Gaines-Day. Do managed bees have negative effects on wild bees?: A systematic review of the literature. PLOS ONE 2017; 12: 1-32.

597 Fischer B, Taborsky B, Dieckmann U. Unexpected patterns of plastic energy allocation in stochastic environments. The American Naturalist 2009; 173: E108-20.

598 Alonso S, Dohoo I, Lindahl J, Verdugo C, Akuku I, Grace D. Prevalence of tuberculosis, brucellosis and trypanosomiasis in cattle in tanzania: A systematic review and metaanalysis. Animal Health Research Reviews 2016; 17: 16-27. 
599 Pollitt LC, MacGregor P, Matthews K, Reece SE. Malaria and trypanosome transmission: Different parasites, same rules? Trends in Parasitology 2011; 27: 197-203.

600 Schmidt KA, Ostfeld RS. Biodiversity and the dilution effect in disease ecology. Ecology 2001; 82: 609-19.

601 Halsey S. Defuse the dilution effect debate. Nature Ecology \& Evolution 2018; 3. DOI:10.1038/s41559-018-0764-3.

602 Wood CL, Lafferty KD. Biodiversity and disease: A synthesis of ecological perspectives on lyme disease transmission. Trends in Ecology \& Evolution 2013; 28: 23947.

603 Barribeau S, Sadd B, Plessis L, et al. A depauperate immune repertoire precedes evolution of sociality in bees. Genome Biology 2015; 16: 83.

604 Evans JD, Aronstein K, Chen YP, et al. Immune pathways and defence mechanisms in honey bees apis mellifera. Insect Molecular Biology 2006; 15: 645-56. 
Table1. Summary of all included studies based on parasite groupings

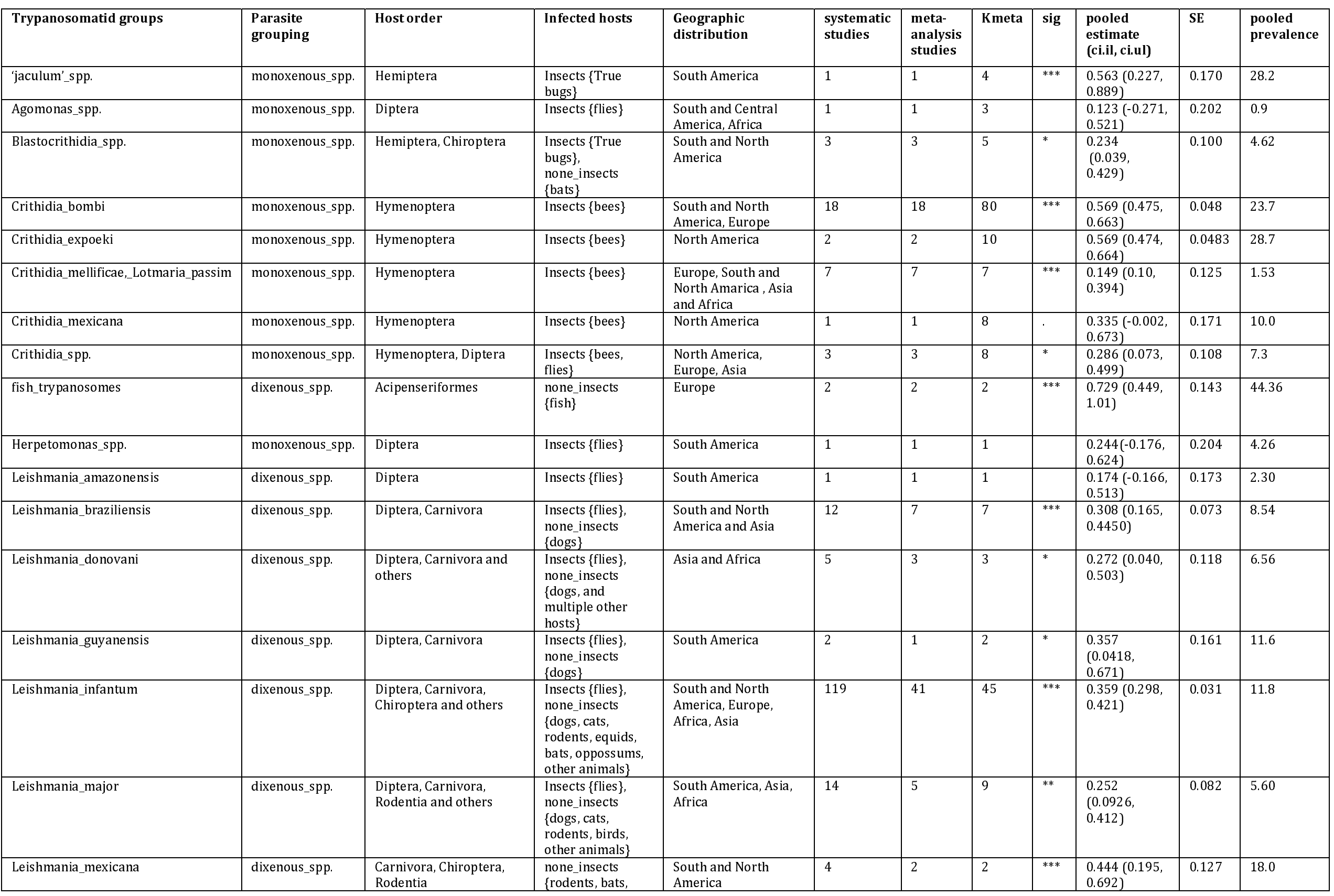




\begin{tabular}{|c|c|c|c|c|c|c|c|c|c|c|c|}
\hline & & & $\operatorname{dog}\}$ & & & & & & & & \\
\hline Leishmania_spp. & dixenous_spp. & $\begin{array}{l}\text { Diptera, Carnivora, } \\
\text { Rodentia and others }\end{array}$ & $\begin{array}{l}\text { insects\{flies\}, } \\
\text { none_insects } \\
\text { \{dogs, cats, } \\
\text { rodents, other } \\
\text { animals\} }\end{array}$ & $\begin{array}{l}\text { South America, Africa, } \\
\text { Europe }\end{array}$ & 62 & 30 & 57 & $* * *$ & $\begin{array}{l}0.335(0.267 \\
0.403)\end{array}$ & 0.035 & 10.2 \\
\hline Leishmania_tropica & dixenous_spp. & Diptera, Carnivora & $\begin{array}{l}\text { insects }\{f l i e s\} \\
\text { none_insects } \\
\text { \{dogs, cats }\end{array}$ & Asia and Africa & 5 & 4 & 4 & . & $\begin{array}{l}0.182(-0.002 \\
0.367)\end{array}$ & 0.094 & 2.60 \\
\hline Leishmania_turanica & dixenous_spp. & Rodentia & $\begin{array}{l}\text { none_insects } \\
\text { \{rodents\} }\end{array}$ & Asia and Africa & 1 & NA & NA & & NA & NA & NA \\
\hline Leptomonas_spp. & monoxenous_spp. & Siphonaptera, Hemiptera & $\begin{array}{l}\text { Insects \{true bugs, } \\
\text { fleas\} }\end{array}$ & South America & 2 & 2 & 5 & . & $\begin{array}{l}0.241(-0.02, \\
0.503)\end{array}$ & 0.134 & 5.04 \\
\hline Lotmaria_passim & monoxenous_spp. & Hymenoptera & Insects $\{$ bees $\}$ & $\begin{array}{l}\text { South and North } \\
\text { America, Asia and } \\
\text { Africa }\end{array}$ & 8 & 8 & 11 & $* * *$ & $\begin{array}{l}0.549(0.393 \\
0.705)\end{array}$ & 0.080 & 26.8 \\
\hline monoxenous_spp. & monoxenous_spp. & Hymenoptera, Hemiptera & $\begin{array}{l}\text { Insects \{bees, true } \\
\text { bugs\} }\end{array}$ & Asia & 2 & 2 & 2 & $* * *$ & $\begin{array}{l}0.567(0.239, \\
0.896)\end{array}$ & 0.168 & 28.5 \\
\hline Phytomonas_spp. & dixenous_spp. & Hemiptera & $\begin{array}{l}\text { Insects \{true } \\
\text { bugs\} }\end{array}$ & South America, Asia & 3 & 3 & 6 & $* *$ & $\begin{array}{l}0.253(0.05 \\
0.455)\end{array}$ & 0.101 & 5.60 \\
\hline Trypanosoma_avium & dixenous_spp. & $\begin{array}{l}\text { Siphonaptera, } \\
\text { Passeriformes }\end{array}$ & $\begin{array}{l}\text { Insects }\{\text { fleas }\} \\
\text { none_insects } \\
\{\text { birds }\}\end{array}$ & $\begin{array}{l}\text { Australia, Europe, } \\
\text { North America }\end{array}$ & 4 & 3 & 3 & . & $\begin{array}{l}0.198(- \\
0.0214, \\
0.418)\end{array}$ & 0.112 & 3.26 \\
\hline Trypanosoma_brucei & dixenous_spp. & $\begin{array}{l}\text { Diptera, Carnivora, } \\
\text { Artiodactyla and others }\end{array}$ & $\begin{array}{l}\text { Insects }\{\text { flies\}, } \\
\text { none_insects } \\
\text { \{dogs, cattle, } \\
\text { sheep, goats, } \\
\text { equids and } \\
\text { others\} }\end{array}$ & Africa and Asia & 40 & 25 & 43 & $* * *$ & $\begin{array}{l}0.161 \\
(0.0943, \\
0.228)\end{array}$ & 0.034 & 1.90 \\
\hline Trypanosoma_chelodinae & dixenous_spp. & NA & $\begin{array}{l}\text { none_insects } \\
\text { \{animals }\end{array}$ & Australia & 1 & NA & NA & & NA & NA & NA \\
\hline Trypanosoma_congolense & dixenous_spp. & $\begin{array}{l}\text { Diptera, Carnivora, } \\
\text { Artiodactyla and others }\end{array}$ & $\begin{array}{l}\text { Insects }\{\text { flies\}, } \\
\text { none_insects } \\
\text { \{dogs, cattle, } \\
\text { sheep, goats, } \\
\text { equids and } \\
\text { others\} }\end{array}$ & Africa & 58 & 38 & 78 & $* * *$ & $\begin{array}{l}0.261(0.205, \\
0.318)\end{array}$ & 0.029 & 6.05 \\
\hline Trypanosoma_copemani & dixenous_spp. & NA & $\begin{array}{l}\text { none_insects } \\
\text { \{animals\} }\end{array}$ & Australia & 1 & 1 & 1 & . & $\begin{array}{l}0.373(- \\
0.0239, \\
0.770)\end{array}$ & 0.203 & 12.7 \\
\hline Trypanosoma_cruzi & dixenous_spp. & $\begin{array}{l}\text { Hemiptera, Chiroptera, } \\
\text { Carnivora }\end{array}$ & $\begin{array}{l}\text { Insects }\{\text { True } \\
\text { bugs }\} \\
\text { none_insects } \\
\{\text { dogs, cats, bats }\}\end{array}$ & $\begin{array}{l}\text { South, Central and } \mathrm{n} \\
\text { North America }\end{array}$ & 50 & 33 & 39 & $* * *$ & $\begin{array}{l}0.357(0.290 \\
0.423)\end{array}$ & 0.034 & 11.6 \\
\hline Trypanosoma_culicavium & dixenous_spp. & Diptera & Insects $\{$ flies $\}$ & Australia & 1 & 1 & 2 & & $\begin{array}{l}0.218(-0.114 \\
0.550)\end{array}$ & 0.169 & 4.14 \\
\hline Trypanosoma_dionisii & dixenous_spp. & Chiroptera & $\begin{array}{l}\text { none_insects } \\
\{\text { bats }\end{array}$ & $\begin{array}{l}\text { South and North } \\
\text { America }\end{array}$ & 3 & 3 & 5 & $* * *$ & $\begin{array}{l}0.423(0.227, \\
0.619)\end{array}$ & 0.100 & 16.30 \\
\hline Trypanosoma_equiperdum & dixenous_spp. & Perissodactyla & $\begin{array}{l}\text { none_insects } \\
\text { \{equids\} }\end{array}$ & Asia & 1 & 1 & 1 & & $\begin{array}{l}0.224(-0.173, \\
0.621)\end{array}$ & 0.203 & 4.30 \\
\hline Trypanosoma_evansi & dixenous_spp. & $\begin{array}{l}\text { Artiodactyla, } \\
\text { Perissodactyla and } \\
\text { others }\end{array}$ & $\begin{array}{l}\text { none_insects } \\
\text { \{equids, camels, } \\
\text { dogs, cattle, goats, } \\
\text { sheep, buffaloes } \\
\text { and animals\} }\end{array}$ & $\begin{array}{l}\text { South America, Africa, } \\
\text { Asia and Europe }\end{array}$ & 63 & 32 & 46 & $* * *$ & $\begin{array}{l}0.339(0.272, \\
0.405)\end{array}$ & 0.034 & 10.50 \\
\hline Trypanosoma_everetti & dixenous_spp. & Passeriformes & $\begin{array}{l}\text { none_insects } \\
\{\text { birds }\}\end{array}$ & Africa & 1 & 1 & 1 & & $\begin{array}{l}0.0394(- \\
0.358,0.437)\end{array}$ & 0.203 & 0.000 \\
\hline Trypanosoma_evotomys & dixenous_spp. & Rodentia & $\begin{array}{l}\text { none_insects } \\
\text { \{rodents }\end{array}$ & Europe & 1 & 1 & 1 & $*$ & $\begin{array}{l}0.399(0 \\
0.798)\end{array}$ & 0.204 & 14.60 \\
\hline
\end{tabular}




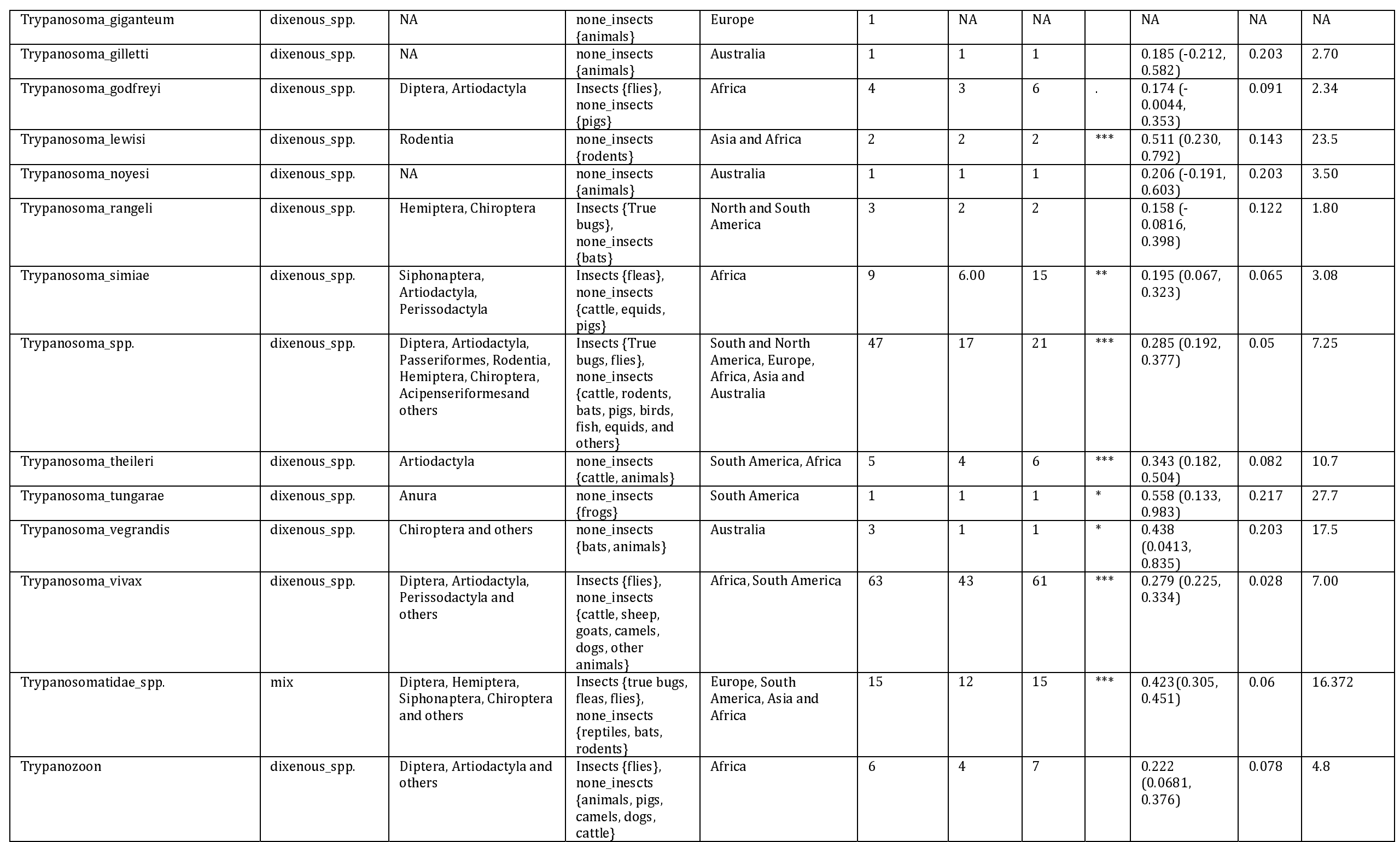

Parasite grouping as extracted from systematically ( 51 level) and quantitatively ( 47 level) included studies. Parasite groups ending with "spp." are trypanosomatids with no enough information to break them down to the exact parasite taxa/group. Systematic and quantitative summary of the main features are outlined in for each group. 
bioRxiv preprint doi: https://doi.org/10.1101/2021.04.29.440076; this version posted May 5, 2021. The copyright holder for this preprint (which was not certified by peer review) is the author/funder, who has granted bioRxiv a license to display the preprint in perpetuity. It is made available under aCC-BY-NC-ND 4.0 International license.

Table2: Pooled prevalence for several subgroup analysis

\begin{tabular}{|c|c|c|c|c|c|c|c|}
\hline \multicolumn{8}{|l|}{ Analysis 1} \\
\hline Host grouping & $k$ & $\begin{array}{l}\text { pooled } \\
\text { estimate } \\
\text { (Cl.lb, Cl.ub) }\end{array}$ & Microscopic (\%) & $\begin{array}{l}\text { pooled } \\
\text { estimate } \\
\text { (Cl.lb, Cl.ub) }\end{array}$ & $\begin{array}{l}\text { Molecular } \\
\text { (\%) }\end{array}$ & (t-test) & Sig \\
\hline Insects & 313 & $\begin{array}{l}0.409(0.352, \\
0.466)\end{array}$ & 14.9 & $\begin{array}{l}0.332(0.282, \\
0.382)\end{array}$ & 9.64 & 0.0002 & $* * *$ \\
\hline Non-insects & 229 & $\begin{array}{l}0.120(0.361, \\
0.448)\end{array}$ & 0.642 & $\begin{array}{l}0.405 \text { (0.361, } \\
0.448)\end{array}$ & 14.9 & $<.0001$ & $* * *$ \\
\hline \multicolumn{8}{|l|}{ Analysis 2} \\
\hline Host grouping & $\kappa$ & $\begin{array}{l}\text { pooled } \\
\text { estimate } \\
\text { (Cl.lb, Cl.ub) }\end{array}$ & $\begin{array}{l}\text { Dixenous } \\
\text { (\%) }\end{array}$ & $\begin{array}{l}\text { pooled } \\
\text { estimate } \\
\text { (Cl.Ib, Cl.ub) }\end{array}$ & Monoxenous (\%) & (t-test) & Sig \\
\hline Insects & 313 & $\begin{array}{l}0.280(0.228, \\
0.333)\end{array}$ & 6.61 & $\begin{array}{l}0.483(0.414, \\
0.552)\end{array}$ & 20.9 & $<.0001$ & $* * *$ \\
\hline Flies & 155 & $\begin{array}{l}0.232(0.194 \\
0.270)\end{array}$ & 4.80 & $\begin{array}{l}0.173(- \\
0.0226, \\
0.244)\end{array}$ & 2.45 & 0.438 & \\
\hline Truebugs & 33 & $\begin{array}{l}0.357(0.265, \\
0.449)\end{array}$ & 11.5 & $\begin{array}{l}0.358(0.170, \\
0.547)\end{array}$ & 11.6 & 0.991 & \\
\hline \multicolumn{8}{|l|}{ Analysis 3 * } \\
\hline Parasite grouping & $\kappa$ & $\begin{array}{l}\text { pooled } \\
\text { estimate } \\
\text { (Cl.lb, Cl.ub) }\end{array}$ & $\begin{array}{l}\text { Insects } \\
\text { (\%) }\end{array}$ & $\begin{array}{l}\text { pooled } \\
\text { estimate } \\
\text { (Cl.lb, Cl.ub) }\end{array}$ & Non-insects (\%) & (t-test) & Sig \\
\hline Dixenous spp & 390 & $\begin{array}{l}0.244(0.216, \\
0.272)\end{array}$ & 5.51 & $\begin{array}{l}0.316(0.290, \\
0.342)\end{array}$ & 9.38 & 0.0001 & $* * *$ \\
\hline Leishmania spp. & 125 & $\begin{array}{l}0.162(0.114, \\
0.210)\end{array}$ & 2.02 & $\begin{array}{l}0.397 \text { (0.357, } \\
0.438)\end{array}$ & 14.5 & 0.0001 & $* * *$ \\
\hline Trypanosoma spp. $^{1}$ & 226 & $\begin{array}{l}0.208(0.177, \\
0.240)\end{array}$ & 4.09 & $\begin{array}{l}0.248(0.219, \\
0.277)\end{array}$ & 5.85 & 0.0001 & $* * *$ \\
\hline Trypanosoma cruzi & 39 & $\begin{array}{l}0.394(0.285, \\
0.502)\end{array}$ & 14.51 & $\begin{array}{l}0.294(0.201, \\
0.388)\end{array}$ & 8.17 & 0.1731 & \\
\hline \multicolumn{8}{|l|}{ Analysis 4} \\
\hline Bees Groups & $\kappa$ & $\begin{array}{l}\text { pooled } \\
\text { estimate } \\
\text { (CI.lb, Cl.ub) }\end{array}$ & $\begin{array}{l}\text { Wild } \\
\text { (\%) }\end{array}$ & $\begin{array}{l}\text { pooled } \\
\text { estimate } \\
\text { (Cl.lb, Cl.ub) }\end{array}$ & Managed (\%) & (t-test) & Sig \\
\hline All & 123 & $\begin{array}{l}0.554(0.440, \\
0.668) \\
\end{array}$ & 26.8 & $\begin{array}{l}0.505(0.207, \\
0.804)\end{array}$ & 22.2 & 0.754 & \\
\hline Honeybee & 17 & $\begin{array}{l}0.631(0.448, \\
0.815)\end{array}$ & 34.2 & $\begin{array}{l}0.481(0.082, \\
0.880)\end{array}$ & 20.1 & 0.502 & \\
\hline Bumblebee & 106 & $\begin{array}{l}0.530(0.398, \\
0.663)\end{array}$ & 24.4 & $\begin{array}{l}0.527(0.113, \\
0.941)\end{array}$ & 24.2 & 0.991 & \\
\hline
\end{tabular}

* dixenous species with prevalence data from both insects and non-insects

${ }^{1}$ Prevalence data for Trypanosoma cruzi are not included here

All of the analysis were done using meta-regressions with random effect model and an appropriate nested random design. $\mathrm{K}$ is the total prevalence data included in the analysis in each row. 